\title{
Novel Polymer Sorbents with Imprinted Task-Specific Ionic Liquids for Metal Removal
}

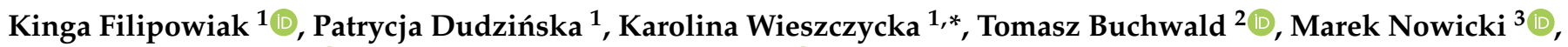 \\ Aneta Lewandowska ${ }^{1}$ (D) and Agnieszka Marcinkowska ${ }^{1}$ (D) \\ 1 Institute of Chemical Technology and Engineering, Poznan University of Technology, 60-965 Poznan, Poland; \\ kinga.m.filipowiak@doctorate.put.poznan.pl (K.F.); parycja.dudzinska@student.put.poznan.pl (P.D.); \\ aneta.b.lewandowska@doctorate.put.poznan.pl (A.L.); agnieszka.marcinkowska@put.poznan.pl (A.M.) \\ 2 Institute of Materials Research and Quantum Engineering, Poznan University of Technology, \\ 60-965 Poznan, Poland; tomasz.buchwald@put.poznan.pl \\ 3 Faculty of Materials Engineering and Technical Physics, Poznan University of Technology, \\ 60-965 Poznan, Poland; marek.nowicki@put.poznan.pl \\ * Correspondence: karolina.wieszczycka@put.poznan.pl; Tel.: +48-61-665-36-88
}

check for updates

Citation: Filipowiak, K.; Dudzińska, P.; Wieszczycka, K.; Buchwald, T.;

Nowicki, M.; Lewandowska, A.;

Marcinkowska, A. Novel Polymer

Sorbents with Imprinted

Task-Specific Ionic Liquids for Metal Removal. Materials 2021, 14, 5008 .

https://doi.org/10.3390/

ma14175008

Academic Editor: Zhenghong Huang

Received: 27 July 2021

Accepted: 25 August 2021

Published: 2 September 2021

Publisher's Note: MDPI stays neutral with regard to jurisdictional claims in published maps and institutional affiliations.

Copyright: (c) 2021 by the authors. Licensee MDPI, Basel, Switzerland This article is an open access article distributed under the terms and conditions of the Creative Commons Attribution (CC BY) license (https:// creativecommons.org/licenses/by/ $4.0 /)$

\begin{abstract}
In this paper, the potential of novel polymer sorbents with the imprinted IL-functional group for the removal of $\mathrm{Cu}(\mathrm{II}), \mathrm{Cd}(\mathrm{II})$, and $\mathrm{Zn}$ (II) from aqueous solutions was investigated by batch mode. The sorbents were fabricated by direct reaction of the prepared polymer matrix (poly(vinylbenzyl chloride-divinylbenzene), VBC, and poly(vinylbenzyl bromide-divinylbenzene), $\mathrm{VBBr}$ ) with 1-(3- or 4-pyridyl)undecan-1-one and oxime of 1-(3- or 4-pyridyl)undecan-1-one. The Fourier Transform Infrared Spectroscopy (FT-IR), Raman Spectroscopy (Raman), Thermogravimetric Analysis (TG), Differential Scanning Calorimetry (DSC), and Scanning Electron Microscopy (SEM) techniques were used to show functionality and stability of the sorbents. The materials were also characterized by contact-angle goniometry, X-rayphotoelectron spectroscopy (XPS), and Zeta potential analysis. The removal of $\mathrm{Cd}(\mathrm{II}), \mathrm{Cu}(\mathrm{II})$, and $\mathrm{Zn}(\mathrm{II})$ was monitored and optimized under the influence of several operational controlling conditions and factors such as $\mathrm{pH}$, shaking time, temperature, initial metal ions concentration, and counter-ions at the functional group. The results obtained confirmed the very high potential of the sorbents; however, the properties depend on the structure of the functional group. The tested sorbents showed fast kinetics, significant capacity at $25^{\circ} \mathrm{C}(84 \mathrm{mg} / \mathrm{g}$ for the $\mathrm{Zn}$ (II) sorption with VBC-Ox4.10, $63 \mathrm{mg} / \mathrm{g}$ for the Cd(II) sorption with VBBr-Ox3.10, and $69 \mathrm{mg} / \mathrm{g}$ for the $\mathrm{Cu}(\mathrm{II})$ sorption with VBC-K3.10), and temperature dependence (even $100 \%$ increase in capacity values at $45^{\circ} \mathrm{C}$ ). The selected sorbent can be regenerated without a significant decrease in the metal removal efficiency.
\end{abstract}

Keywords: ionic liquids; sorbents; resins; metals removal; sorption; isotherm; kinetic

\section{Introduction}

Heavy metals have a wide range of applications in various areas, such as medicine, technology, and the industry [1]. They are also efficient catalysts because of their selectivity and their high activity [2]. Unfortunately, due to the huge technological development, heavy metal ions have become a threat to the natural environment and thus to human health. Pollutants containing ions of heavy metals such as chromium, lead, copper, or cadmium are formed in chemical factories, batch production, mining, and metallurgy [3]. They enter the ground water along with the wastewater from these industries. Heavy metals are highly toxic, not biodegradable, and bioaccumulative. They cause various diseases and disorders, such as cancer [4]. They are very toxic even at a very low concentration. Due to this consideration, many new water treatment processes are being introduced. Conventional methods include precipitation, electrochemical reduction and membrane separation, adsorption, and ion exchange [5]. These methods have limits related to the 
nature of the metals, their concentration, and the composition of the solution. For example, during precipitation, other contaminants are created due to the use of chemical reagents [6]. The low cost of naturally occurring sorbents encourages researchers to modify their surface, resulting in new sorbents. Adsorption techniques using chelating groups on sorbents surface are recently very popular in separation chemistry thanks to the low cost, high adsorption capacity, good regeneration, and good selectivity for certain metal ions [7]. Some of the modified sorbents are silica gel [8], activated carbon [9], zeolites [10], and cellulose derivatives [11]. The functionalization of synthetic sorbents with ionic liquids is an example of process that also fits into the idea of green chemistry. Ionic liquids are alternative media in separation applications as a result of its advantages, such as non-inflammability and non-toxicity [12]. Ionic liquids (IL) such as quaternary pyridinium salts have suitable physicochemical properties for use in the separation processes of organic and inorganic compounds. Particularly high extraction properties and specific mechanism in a liquidliquid system caused the immobilization of ILs on silica or polymer supports [13-15]. By incorporating organic functional groups onto the silica surface, there is an increase in uptake of metals and $\mathrm{CO}_{2}$, which improves the process efficiency [16-20], while a combination of polymers and ionic liquids can simultaneously remove both inorganic and organics pollutants from water [21]. The immobilization on polymer supports was performed both in the case of commercial ILs as well as newly designed compounds, although in the first group, mainly impregnation was used. An example is the immobilization of Cyphos IL-101 (tetradecyl(trihexyl)phosphonium chloride) onto Amberlite XAD series sorbents and $\mathrm{Pd}(\mathrm{II}), \mathrm{Fe}(\mathrm{III}), \mathrm{Hg}(\mathrm{II}), \mathrm{Au}(\mathrm{III})$, and $\mathrm{Pt}(\mathrm{IV})$ sorption from $\mathrm{HCl}$ [22-25]. Our previous studies also confirmed that the functionalization of PS-DVB by the incorporation and encapsulation of ionic liquid extractant $[26,27]$ or by quaternization with IL-precursors to obtain the IL-functionalized polymers enabled us to obtain efficient sorbents $[13,28]$. The most interesting results were obtained for chromium removal. It was demonstrated that the sorbents functionalized by hydrophilic pyridylketones were responsible not only for adsorption of chromium(VI) but also for a reduction to a less toxic $\mathrm{Cr}(\mathrm{III})$. Therefore, the continuation of research, especially in the field of further modification of the functional group and selection of the counter-anion of the quaternary nitrogen in order to obtain novel efficient and stable sorbents, is justified.

Therefore, the goal of this study was to synthesize novel sorbents, copolymers of vinylbenzyl chloride or vinylbenzyl bromide, and divinylbenzene modified by pyridine derivatives consisting of a 3- and 4-position ketone or oxime group for $\mathrm{Cu}(\mathrm{II}), \mathrm{Cd}(\mathrm{II})$, and $\mathrm{Zn}$ (II) removal. In the scope of a sorption study, the effect of several parameters including initial $\mathrm{pH}$, metals ions concentration, contact time, and sorption temperature are studied in detail and are discussed to evaluate the efficiency of metal ion removal.

\section{Materials and Methods}

\subsection{Chemicals}

4-(Chloromethyl)styrene (90\%, Sigma Aldrich, Darmstadt, Germany) and 1,4-divinylbenzene (85\%, Sigma Aldrich, Darmstadt, Germany) were passed through neutral alumina column to remove inhibitor. Tetrahydrofuran (p.a., Sigma Aldrich, Darmstadt, Germany) was distilled over sodium and benzophenone. Benzoyl peroxide (Fluka, Buchs, Switzerland) was dried for $24 \mathrm{~h}$ at $60^{\circ} \mathrm{C}$ before use. $\mathrm{LiBr}$ (99\%, anhydrous, Sigma Aldrich, Darmstadt, Germany), toluene ( $99.9 \%$, POCh, Poznan, Poland), and methanol (99.9\%, POCh, Poznan, Poland) were used without purification. 1-(4-pyridyl)undecan-1-one, 1-(3-pyridyl)undecan-1-one, and their oximes were synthesized following a procedure described in [29-31]. Copper(II) nitrate $\left(\mathrm{Cu}\left(\mathrm{NO}_{3}\right)_{2} \cdot 6 \mathrm{H}_{2} \mathrm{O}\right.$, p.a.) cadmium(II) nitrate $\left(\mathrm{Cd}\left(\mathrm{NO}_{3}\right)_{2} \cdot 4 \mathrm{H}_{2} \mathrm{O}, 99.997 \%\right)$, and zinc(II) nitrate $\left(\mathrm{Zn}\left(\mathrm{NO}_{3}\right)_{2} \cdot 6 \mathrm{H}_{2} \mathrm{O}\right.$, p.a.) were purchased from Sigma-Aldrich (Darmstadt, Germany). Standard solutions of $\mathrm{Cu}(\mathrm{II}), \mathrm{Cd}(\mathrm{II})$, and $\mathrm{Zn}$ (II) as well as $\mathrm{pH}$ buffers were obtained from Merck KGaA (Darmstadt, Germany). $\mathrm{HCl}(32 \%)$, $\mathrm{NaOH}$, and $\mathrm{NaCl}$ were of analytical grade and were supplied by Chempur, Poland. Ultra-pure water was obtained by using Arium Pro DI purification system (Sartorius, Göttingen, Germany). 


\subsection{Apparatus}

The VBC synthesis, substitution reaction, and functionalization with the pyridine derivatives were confirmed via Raman and FTIR spectroscopy. A Raman spectroscopy analysis was carried out with the use of Renishaw's inVia Raman System. The Raman spectra of all materials were collected in the spectral range from 3200 to $200 \mathrm{~cm}^{-1}$ with lasers emitting $633 \mathrm{~nm}$ and $785 \mathrm{~nm}$. Raman map showing the distribution of VBC modified with Ox3.10 was recorded on a $200 \mu \mathrm{m} \times 200 \mu \mathrm{m}$ surface with a $10 \mu \mathrm{m}$ step size measurement. FT-IR analyses were carried out on a Vertex 70 Spectrometer (Bruker Optics FT-IR) in the range of IR 500-4000 $\mathrm{cm}^{-1}$ with a resolution of $2 \mathrm{~cm}^{-1}$. The elemental composition of fabricated sorbents was determined using the elemental analyzer FLASH EA 1112 Series of Thermo Electron Corporation.

Thermogravimetric investigations were performed on a TG 209 F3 Tarsus analyzer (NETZSCH-Geratebau GmbH, Selb, Germany) in the temperature range of 30-600 ${ }^{\circ} \mathrm{C}$. Approximately $10 \mathrm{mg}$ of sample was placed in $\mathrm{Al}_{2} \mathrm{O}_{3}$ crucible and was analyzed with a heating rate of $10{ }^{\circ} \mathrm{C} / \mathrm{min}$ under nitrogen atmosphere (flow of purge gas $20 \mathrm{~mL} / \mathrm{min}$ and protective gas $10 \mathrm{~mL} / \mathrm{min}$ ). A DSC analysis of 5-10 $\mathrm{mg}$ of the prepared material was performed on DSC1 (Mettler Toledo, Switzerland) in the temperature range $25-200{ }^{\circ} \mathrm{C}$ with a heating rate of $20^{\circ} \mathrm{C} / \mathrm{min}$ under argon atmosphere $(20 \mathrm{~mL} / \mathrm{min})$. The heat of evaporation of residual solvents used in the synthesis was determined from the first run of DSC measurement.

The atomic absorption spectrometer (AAS—ContrAA 300, Analytik Jena, Jena, Germany) was used for the measurement of metal ion concentrations in aqueous samples. Zeta potential measurements were conducted using a ZetaSizer Nano ZS (Malvern, UK) to study the surface charge changes of the final materials under different $\mathrm{pH}$. The morphology of the sorbents was studied with an FEI Quanta 250 FEG scanning electron microscope. Images were taken for secondary electrons in the low vacuum mode at a pressure of $70 \mathrm{~Pa}$. An accelerating voltage of $20 \mathrm{kV}$ was used. The XPS analyses were used to confirm which moiety located on the sorbents surface was responsible for the metal adsorption. The analyses were carried out in a PHI VersaProbeII Scanning XPS system using monochromatic $\mathrm{Al} \mathrm{K} \alpha(1486.6 \mathrm{eV}) \mathrm{X}$-rays focused on a $100 \mu \mathrm{m}$ spot. The photoelectron take-off angle was $45^{\circ}$, and the pass energy in the analyzer was set to $117.50 \mathrm{eV}$ for survey scans and $46.95 \mathrm{eV}$ to obtain high energy resolution spectra for the $\mathrm{C} 1 \mathrm{~s}, \mathrm{~N} 1 \mathrm{~s}, \mathrm{Cl} 2 \mathrm{p}, \mathrm{Br} 2 \mathrm{p}$, and $\mathrm{O} 1 \mathrm{~s}$ regions. A dual beam charge compensation with $7 \mathrm{eV} \mathrm{Ar}^{+}$ions and $1 \mathrm{eV}$ electrons were used to maintain a constant sample surface potential regardless of the sample conductivity.

\subsection{Srobents Fabrication}

The poly(vinylbenzyl chloride-co-divinylbenzene) (VBC) was prepared according to the procedure described in [32]. After the washing and drying procedure, the VBC beads reacted with the equimolar amount of $\mathrm{LiBr}$ in tetrahydrofuran as a diluent. The reaction was supported by the $0.1 \%$ mol PTC catalyst (tetrabutylammonium bromide). After finishing the halogen-exchange reaction, the poly(vinylbenzyl bromide-co-divinylbenzene) beads $(\mathrm{VBBr})$ were collected by centrifugation, washed with methanol, and then dried in a vacuum chamber. The fabricated VBC and VBBr beads, after characterization by elemental analysis to determine the amounts of the chloro- and bromomethyl groups located in the polymers structure, were reacted in toluene with the appropriate amount of 1-(4pyridyl)undecan-1-one (K4.10), 1-(3-pyridyl)undecan-1-one (K3.10), 1-(4-pyridyl)undecan1-one oxime (Ox4.10), and 1-(3-pyridyl)undecan-1-one oxime (Ox3.10) as precursors of the functional groups. The functionalization was carried out at $50{ }^{\circ} \mathrm{C}$ for 7 days in $250 \mathrm{~mL}$ glass reactor equipped with a hot-plate-magnetic stirrer. The purified sorbents were dried at $80^{\circ} \mathrm{C}$ under vacuum overnight and analyzed (FT-IR, Raman, elemental). The procedure used enabled us to obtain the VBC-K3.10, VBC-K4.10, VBC-Ox3.10, VBC-Ox4.10, VBBr$\mathrm{K} 3.10, \mathrm{VBBr}-\mathrm{K} 4.10, \mathrm{VBBr}-\mathrm{Ox} 3.10$, and VBBr-Ox4.10 sorbents. A scheme of the synthesis of the studied sorbents is presented in Figure 1. 


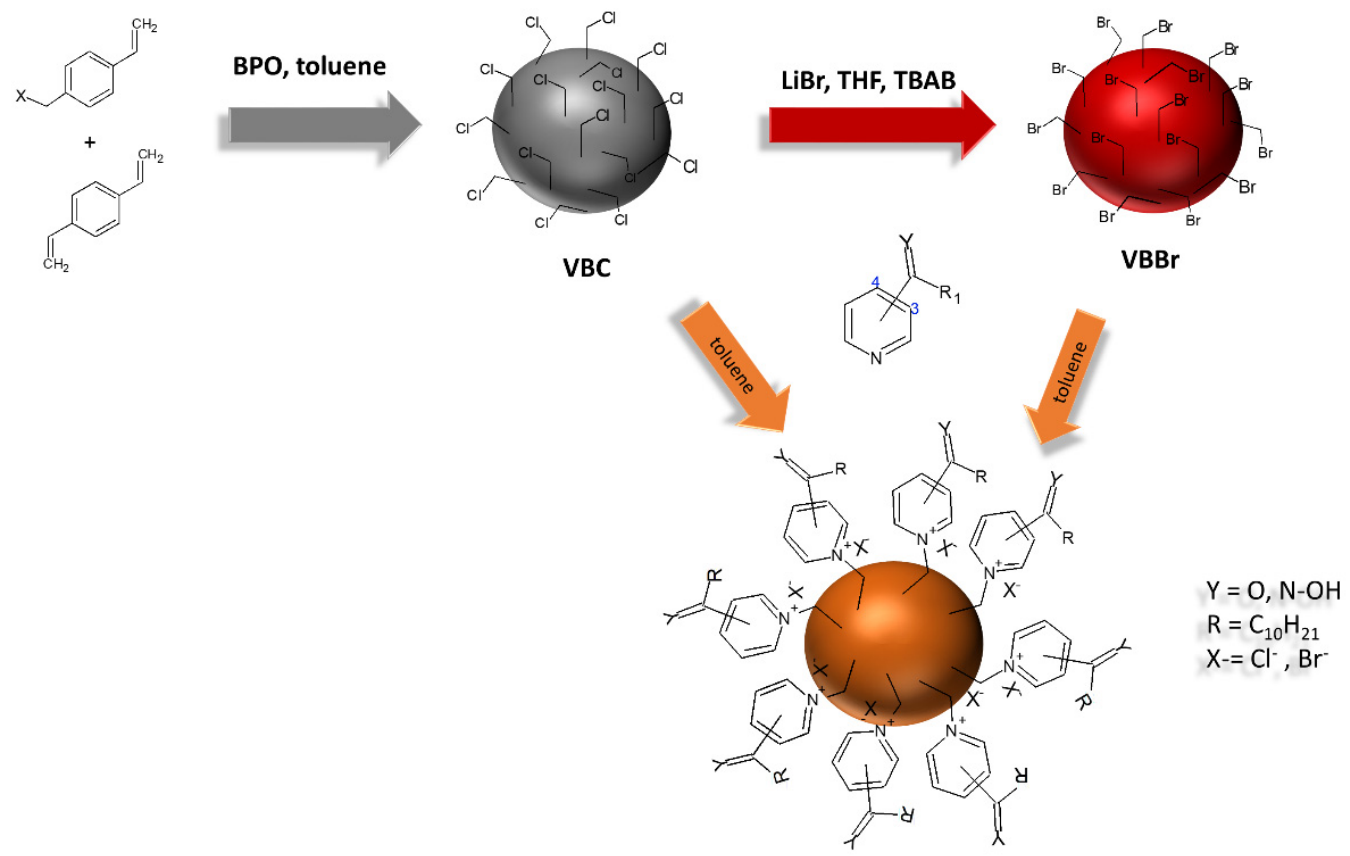

Figure 1. Scheme of the synthesis of the sorbent series VBC and VBBr.

\subsection{Sorption Studies}

Sorption experiments were carried out by employing the batch method by mixing $0.1 \mathrm{~g}$ of the sorbent with $100 \mathrm{~mL}$ of an aqueous solution of $\mathrm{Cu}(\mathrm{II}), \mathrm{Zn}(\mathrm{II})$, and $\mathrm{Cd}(\mathrm{II})$ with variable concentrations of each metal ion at a constant temperature of $23^{\circ} \mathrm{C}$. The adsorption was studied at a different $\mathrm{pH}(1-6)$, times (1-350 min), and metal ion concentrations $(50-200 \mathrm{mg} / \mathrm{L})$ and at constant temperature $\left(23^{\circ} \mathrm{C}\right)$. The working metal concentrations were prepared by appropriate dilution of stock solutions. The $\mathrm{pH}$ of each of the solutions was adjusted to values of $1.0-6.0$ by the dropwise addition of $0.1 \mathrm{M} \mathrm{NaOH}$ or $0.1 \mathrm{M} \mathrm{HCl}$ using the T5 Excellence titrator fitted with $\mathrm{pH}$ electrode. The desorption experiment was conducted for the selected sorbents using different aqueous solutions of $\mathrm{HCl}, \mathrm{NaCl}$, and $\mathrm{Na}_{2} \mathrm{SO}_{4}$. The mixtures were shaken using a temperature controlled shaker (KS 4000 ic control, IKA) at $240 \mathrm{rpm}$ for a period of desired time. After finishing sorption or desorption, the solid phase was separated and the metal ion concentration in the supernatant was determined by atomic absorption measurements using ContrAA 300 (Analytik Jena AG). Each experiment was replicated three times, and the results were averaged. The metal ion removal efficiency $(R)$ and amount of adsorbed metal ions $(Q)$ were calculated using the following equations:

$$
\begin{aligned}
& R=\frac{C_{0}-C_{t}}{C_{0}} \cdot 100 \\
& Q=\frac{\left(C_{0}-C_{t}\right) \cdot V}{m}
\end{aligned}
$$

where $C_{0}$ and $C_{t}(\mathrm{mg} / \mathrm{L})$ are the concentrations of the metal ions before and after contact between the phases at time $t . V$ is the volume of aqueous phase used (L), and $m$ is the mass of the sorbent used $(\mathrm{g})$.

The experimental data were also used to evaluate the kinetics and equilibrium of the sorption (Table 1). The pseudo-first order, pseudo-second order, Elovich, and intra-particle diffusion models were applied to describe the kinetics of the sorption [33]. The equilibrium was modelled using isotherms such as Freundlich, Langmuir, Dubinin-Radushkevich, and Temkin [34]. The nonlinear forms of the models are presented in [35]. Kinetic studies were carried out using $50 \mathrm{mg} / 1$ at $\mathrm{pH} 5$ at $298.15 \mathrm{~K}$. The isotherm experiments were carried out by using different initial concentrations of metal ions $(50-200 \mathrm{mg} / \mathrm{L})$ at $298.15 \mathrm{~K}$ and at a $\mathrm{pH}$ of 5 . 
Table 1. Kinetic and isotherm models with equations used to describe sorption process.

\begin{tabular}{ccc}
\hline Kinetic Model & Equation * & Equation \\
\hline Pseudo-first order & $\mathrm{q}_{\mathrm{t}}=\mathrm{q}_{\mathrm{e}}\left(1-\mathrm{e}^{-\mathrm{k}_{1} \mathrm{t}}\right)$ & $(3)$ \\
Pseudo-second order & $\mathrm{q}_{\mathrm{t}}=\frac{\mathrm{k}_{2} \cdot \mathrm{q}_{\mathrm{e}}^{2}}{1+\mathrm{k}_{2} \cdot \mathrm{q}_{\mathrm{e}}}$ & $(4)$ \\
Elovich & $\mathrm{q}_{\mathrm{t}}=\frac{1}{\beta} \ln (\alpha \beta \mathrm{t})$ & $(5)$ \\
Intra-particle diffusion & $\mathrm{q}_{\mathrm{t}}=\mathrm{k}_{\mathrm{ip}} \mathrm{t}^{\frac{1}{2}}+\mathrm{C}$ & $(6)$ \\
\hline Isotherm model & $\mathrm{q}_{\mathrm{e}}=\frac{\mathrm{q}_{\mathrm{m}} \mathrm{K}_{\mathrm{L}} \mathrm{C}_{\mathrm{e}}}{1+\mathrm{K}_{\mathrm{L}} \mathrm{C}_{\mathrm{f}}}$ & Equation \\
\hline Langmuir & $\mathrm{q}_{\mathrm{e}}=\mathrm{K}_{\mathrm{F}} \mathrm{C}_{\mathrm{e}}^{\frac{1}{n}}$ & $(7)$ \\
Freundlich & $\mathrm{q}_{\mathrm{m}} \mathrm{e}^{-\mathrm{K}_{\mathrm{DR}}\left[\mathrm{RT} \ln \left(1+\frac{1}{\mathrm{C}_{\mathrm{e}}}\right)\right]^{2}}$ & $(8)$ \\
Dubinin-Radushkevich & $\mathrm{q}_{\mathrm{e}}=\frac{\mathrm{RT}}{\mathrm{b}} \ln \left(\mathrm{K}_{\mathrm{T}} \mathrm{C}_{\mathrm{e}}\right)$ & $(9)$ \\
Temkin & $\mathrm{q}_{\mathrm{e}}$ & $(10)$ \\
\hline
\end{tabular}

${ }^{*} \mathrm{q}_{\mathrm{e}}$ and $\mathrm{q}_{\mathrm{t}}(\mathrm{mg} / \mathrm{g})$ are the amount of metal ions removed at equilibrium and at time $\mathrm{t}(\mathrm{min}), \mathrm{k}_{1}$ the pseudo-first order model $\left(\mathrm{min}^{-1}\right), \mathrm{k}_{2}(\mathrm{~g} / \mathrm{mg} \mathrm{min})$ is the pseudo-second order rate constant, $\mathrm{k}_{\text {ip }}$ is the intra-particle diffusion rate constant $\left(\mathrm{mg} / \mathrm{g} \min ^{0.5}\right), \alpha(\mathrm{mg} / \mathrm{g} \mathrm{min})$ is the initial sorption rate constant, and $\beta(\mathrm{g} / \mathrm{mg})$ is the desorption constant. ${ }^{* *} \mathrm{C}_{\mathrm{e}}$ is the equilibrium concentration of adsorbed metal ions. $\mathrm{K}_{\mathrm{L}}(\mathrm{L} / \mathrm{mg}), \mathrm{K}_{\mathrm{F}}\left(\mathrm{mg}^{1-(1 / \mathrm{n})} / \mathrm{gL}^{\mathrm{n}}\right), \mathrm{K}_{\mathrm{DR}}$ $\left(\mathrm{mol}^{2} / \mathrm{J}^{2}\right)$, and $\mathrm{K}_{\mathrm{T}}(\mathrm{L} / \mathrm{g})$ are the appropriate constants. $\mathrm{q}_{\mathrm{m}}$ is the maximum sorption capacity, and $\mathrm{n}$ is the heterogeneity factor.

\section{Results and Discussion}

\subsection{Structural and Thermal Characterization of the Sorbents}

The FTIR spectra confirmed the fabrication of poly(vinylbenzyl chloride-co-divinylbenzene); the substitution of chlorine atom with bromine; and further quaternization of 1-(4-pyridyl)undecan1-one (K4.10), 1-(3-pyridyl)undecan-1-one (K3.10), 1-(4-pyridyl)undecan-1-one oxime (Ox4.10), and 1-(3-pyridyl)undecan-1-one oxime (Ox3.10). In the case of VBC, the spectrum confirmed the presence of a $-\mathrm{CH}_{2} \mathrm{Cl}$ functional group located at the benzene ring. The peak at $1261 \mathrm{~cm}^{-1}$ was attributed to stretching vibrations of the chloromethyl group, and the peak at $802 \mathrm{~cm}^{-1}$ was due to stretching vibrations of $\mathrm{C}-\mathrm{Cl}$. The exchange of $\mathrm{Cl}$ on $\mathrm{Br}$ resulted in a shift of these bands to lower wavenumbers $\left(-\mathrm{CH}_{2} \mathrm{Br}\right.$ and $\mathrm{C}-\mathrm{Br}$ vibrations observed at $1071 \mathrm{~cm}^{-1}$ and $707 \mathrm{~cm}^{-1}$, respectively). Comparing the spectra of $\mathrm{VBC}$ or $\mathrm{VBBr}$, and the sorbents after modification (VBC-K3.10, VBCK4.10, VBC-Ox3.10, VBC-Ox4.10, VBBr-K3.10, VBBr-K4.10, VBBr-Ox3.10, and VBBr-Ox4.10), the peaks at $1600-1605 \mathrm{~cm}^{-1}$ and $1508 \mathrm{~cm}^{-1}$ assigned to the $C=N$ and $C=C$ ring stretching vibrations of pyridine, respectively, were indicated. Moreover, in the case of the VBC-K3.10, VBC-K4.10, VBBr-K3.10, and VBBr-K4.10 resins, the peaks at $1720,1722,1701$, and at $1702 \mathrm{~cm}^{-1}$, respectively, were assigned to the $\mathrm{C}=\mathrm{O}$ stretching vibrations of ketone group were observed. In contrast, for VBC-Ox3.10, VBC-Ox4.10, VBBr-Ox3.10, and VBBr-Ox4.10, the bands corresponding to oxime $\mathrm{C}=\mathrm{N}$ were observed at $1635,1647,1632$, and $1639 \mathrm{~cm}^{-1}$, respectively.

Obtaining the materials at each stage of the synthesis was also confirmed by Raman analysis (Figure 2a-d). The Raman spectra of VBC and VBBr show differences in the position of the bands. In the spectra of $\mathrm{VBC}$, the bands assigned to the stretching vibrations of $-\mathrm{CH}_{2} \mathrm{Cl}$ and $\mathrm{C}-\mathrm{Cl}$ are present at $1265 \mathrm{~cm}^{-1}$ and $674 \mathrm{~cm}^{-1}$, respectively. In turn, in the spectra of $\mathrm{VBBr}$, the bands assigned to $-\mathrm{CH}_{2} \mathrm{Br}$ and $\mathrm{C}-\mathrm{Br}$ are shifted to lower wavenumbers and are indicated at 1227 and $609 \mathrm{~cm}^{-1}$, respectively. In the Raman spectra of all modified $\mathrm{VBBr}$ and VBC, there are bands related to VBBr and VBC, and the new bands at 1030 and $1117 \mathrm{~cm}^{-1}$ are assigned to $\mathrm{C}-\mathrm{H}$ vibrations of the pyridine ring in $\mathrm{O} 3.10$ and $\mathrm{Ox} 4.10$, respectively. The Raman map (Figure 2c) presenting the ratio of the $1001 \mathrm{~cm}^{-1}$ band intensity (related to VBC) to the $1030 \mathrm{~cm}^{-1}$ band intensity (related to Ox3.10) (Figure 2d) was used to evaluate the effectiveness of VBC modification. The Raman map confirms that the VBC was successfully modified. The $1030 \mathrm{~cm}^{-1}$ band is observed in all Raman spectra collected on the entire analyzed surface. The other Raman spectroscopy results also confirm that VBC as well as VBBr was efficiently modified with other compounds. 
a

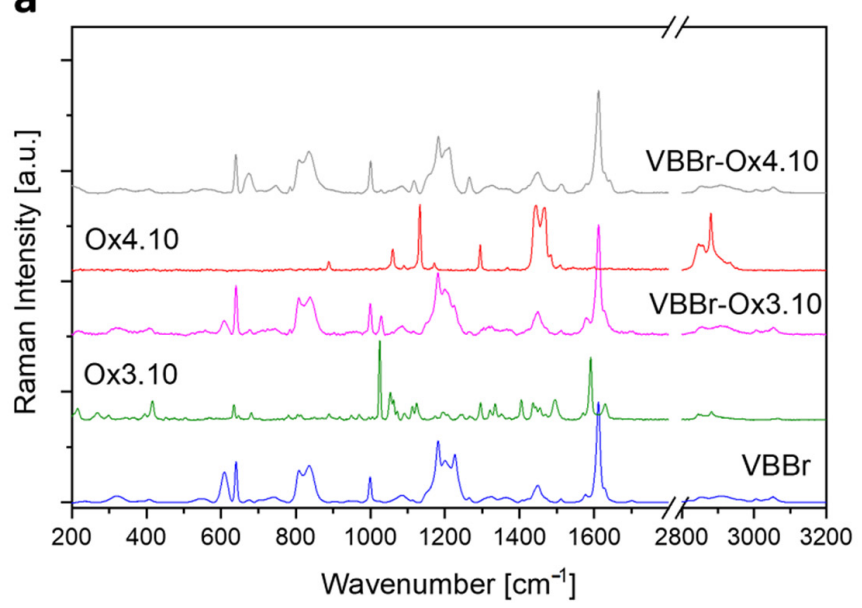

b

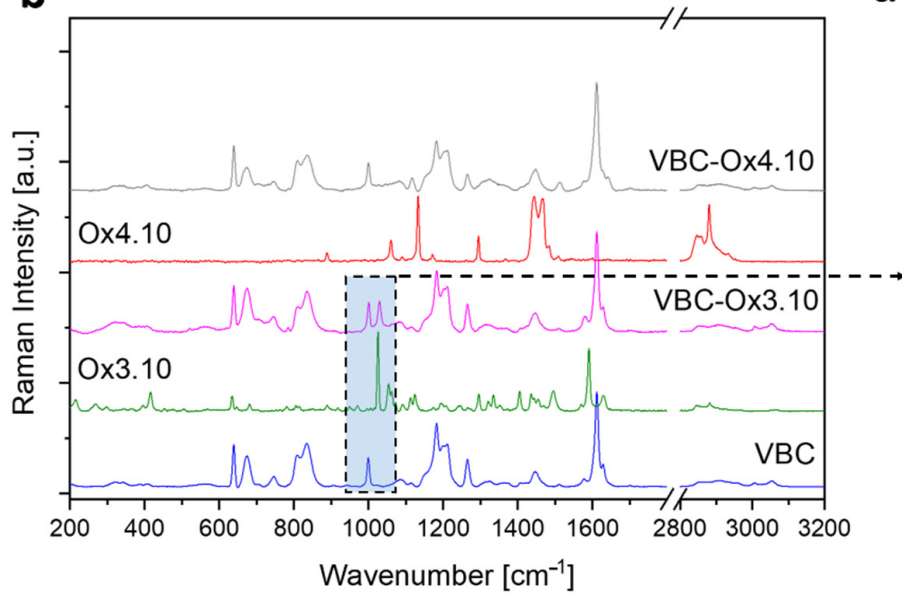

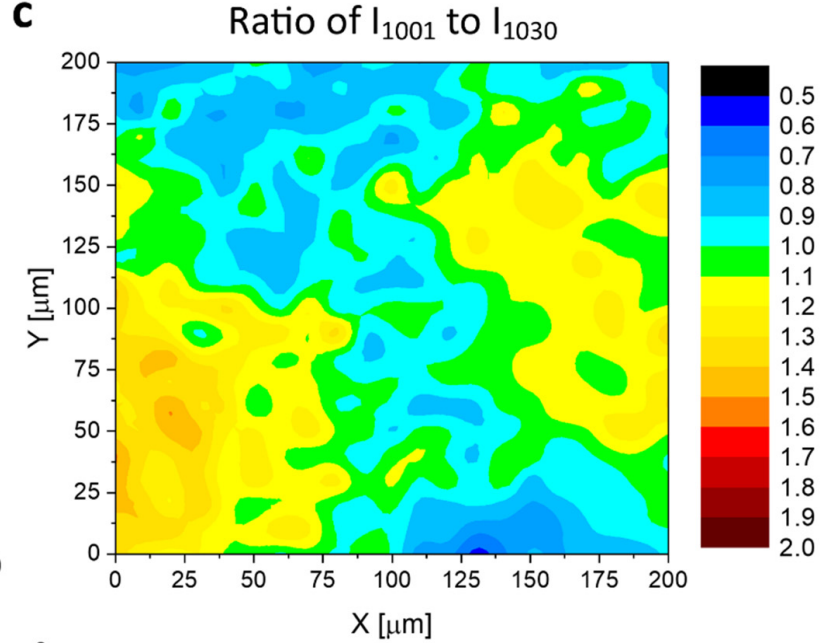

d

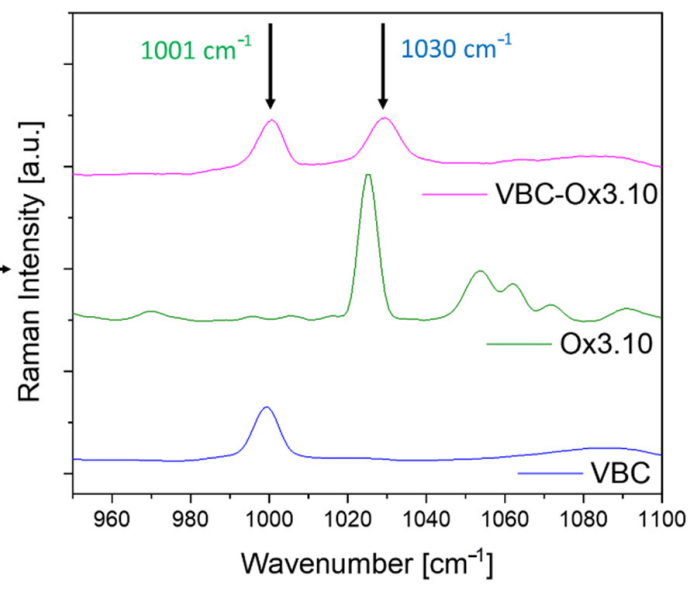

Figure 2. Raman spectra of $\operatorname{VBBr}(\mathbf{a})$ and $\operatorname{VBC}(\mathbf{b})$ before and after modification with Ox3.10 and Ox4.10, Raman map of VBC-Ox3.10 (c) and Raman spectra with marked bands on the basis of which the map was obtained (d).

The surface morphologies of $\mathrm{VBC}$ and $\mathrm{VBBr}$ particles were observed by SEM, and representative images are presented in Figure 3. In the case of VBC, it was observed that more than 90 percent of the imaged grains are in the size range of 175-300 micrometers (diameter). The mean value of the grain diameter is 258 microns, with an average deviation of 46 microns. The shape of the grains is perfectly spherical, and there is an occasional defect that looks similar to a dent from an adjacent ball. Since there is a small population of spheres connected, those with a slight deformation of the shape may be the effect of separation of previously connected balls. The surface of the grains is smooth, and it contains a small number of pores in the form of round holes with a diameter of up to about 1 micrometer. There is also a small population (less than $10 \%$ ) of very small spheres: 25-75 micrometers. In the case of $\mathrm{VBBr}$, it was indicated that the condition of the substitution reaction caused partial damage to the VBC spheres. Approximately $50 \%$ of the beads have been fragmented into several pieces large enough to see areas that were previously the surface of the ball on them. There was no complete decomposition, only cracking. Sizes similar to the undissolved VBC with a mean diameter of 133 micrometers with a mean variation of 31 micrometers and a diameter spread of 90-250 micrometers. The size and shape of the crumbs indicate that the balls break into several or a dozen parts. The pores inside the broken balls are of a spherical shape, constituting a small part of the volume of the spheres. These voids have a diameter of 1 to 5 micrometers. The fractures themselves contain sharp edges, typical for brittle fracture. The surface of undamaged spheres has no holes visible on the VBC. The analysis of the VBC and VBBr 
after functionalization with the pyridine derivatives did not reveal any further changes in the morphology and shape of the particles.

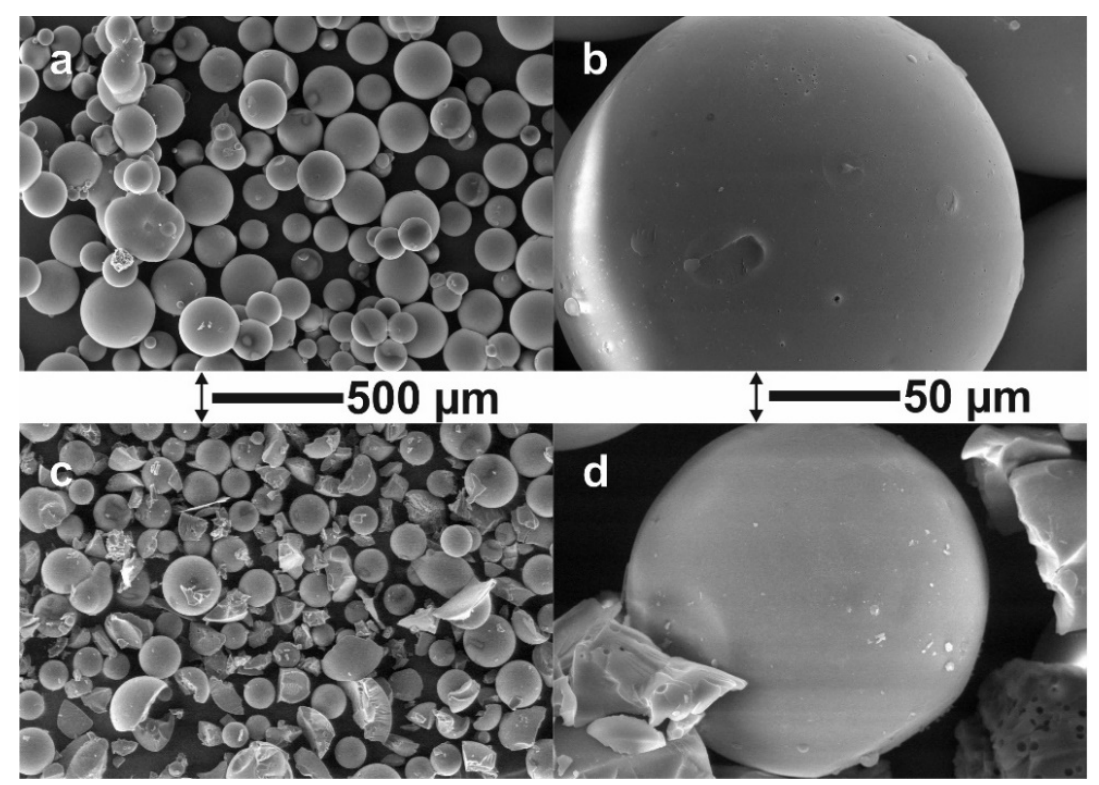

Figure 3. SEM Images of $\operatorname{VBC}(\mathbf{a}, \mathbf{b})$ and $\operatorname{VBBr}(\mathbf{c}, \mathbf{d})$.

The measurement of the contact angle provides information on the wettability of water on the sorbent surface. The results obtained show a close correlation between the structure of functional groups and the hydrophilicity of the sorbents (Table S1). The presence of bromide counter ions on the polymer surface causes poor surface wetting $\left(\theta>90^{\circ}\right)$. On the other hand, the surface of the VBC series sorbents shows a contact angle much below $90^{\circ}$, which allows us to classify these materials as hydrophilic. Moreover, substitution on the 4-position of the pyridine ring yields higher contact angle values than that observed for 3-analogue, and the ketones are less hydrophilic than the corresponding oximes.

The thermal stability of the synthetized materials was examined by thermogravimetric analysis (TGA). Figure 4 shows the TGA curves of two types of copolymers VBC and VBBr, and products of their modification with the appropriate pyridine derivative. Figure 4 shows the weight loss of the materials when heated up to $600{ }^{\circ} \mathrm{C}$ under nitrogen atmosphere. As can be seen, copolymers present three steps of decomposition. The first one, occurring at a temperature below $100{ }^{\circ} \mathrm{C}$, can be attributed to the evaporation of the residual solvents used during the synthesis and purification of the sorbents, which are absorbed in samples. The next two are weight losses of copolymer. At a lower temperature range, the decomposition of pendant groups and then decomposition of the crosslinked network of copolymer occur. The initial decomposition temperatures were taken as onset of the weight loss and presented in Table 2. The thermal stability of both copolymers is in the temperature above $300{ }^{\circ} \mathrm{C}$, and the copolymer $\mathrm{VBC}$ has greater thermal stability $\left(\mathrm{T}_{\text {onset }}=382^{\circ} \mathrm{C}\right)$ than the copolymer with VBBr by approximately $50^{\circ} \mathrm{C}\left(\mathrm{T}_{\text {onset }}=336^{\circ} \mathrm{C}\right)$. Modification of the copolymers structure causes a decrease in the thermal stability of the starting polymers and the appearance of additional degrees of decomposition on the curves related to the grafted structures. Despite the differences in the thermal resistance of copolymers, their modification results in the obtaining materials with similar resistance to thermal decomposition, which is probably related to the chemical structure of the substituents introduced into the copolymers as a result of the modification. All investigated sorbents are stable up to the temperature of approximately $160{ }^{\circ} \mathrm{C}$, with the $\mathrm{Ox} 3.10$ derivatives having the highest stability, i.e., $\mathrm{T}_{\text {onset }}$ close to $200^{\circ} \mathrm{C}$. Therefore, they are characterized by a higher thermal stability than the commercial Lewatit TP 207 (thermal stability up to $80^{\circ} \mathrm{C}$ ) or Amberlyst 15 resin ( $\mathrm{T}_{\text {onset }}$ $\left.150^{\circ} \mathrm{C}\right)$. 

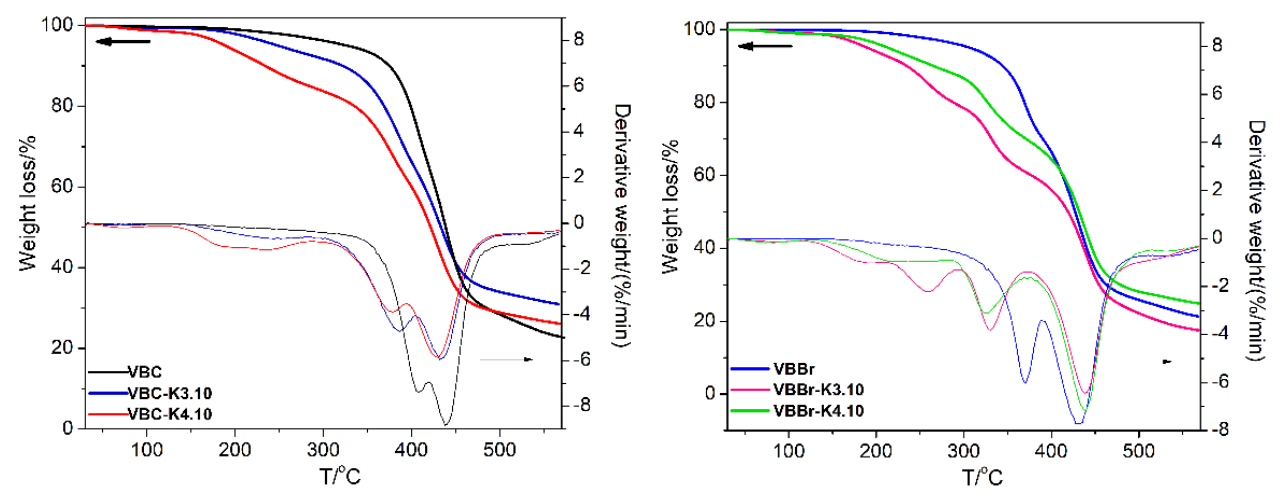

Figure 4. Thermogravimetric curves unmodified and modified VBC and VBBr with K3.10 and K4.10.

Table 2. Thermal properties of sorbents (and for comparison commercial resins).

\begin{tabular}{ccccc}
\hline & $\mathbf{T}_{\mathbf{\text { onset}}}{ }^{\circ} \mathbf{C}$ & $\mathbf{H p}^{* *}, \mathbf{J} \mathbf{g}$ & $\mathbf{T p}^{* *}{ }^{\circ} \mathbf{C}$ & Ref. \\
\hline VBC & 382.3 & 23.1 & 83.9 & \\
VBC-K3.10 & 185.4 & 12.4 & 88.3 & \\
VBC-K4.10 & 159.7 & 26.3 & 100.9 & \\
VBC-Ox3.10 & 193.8 & 26.1 & 93.2 & \\
VBC-Ox4.10 & 179.4 & 27.6 & 90.2 & \\
VBBr & 336.4 & 10.1 & 80.0 & \\
VBBr-K3.10 & 158.2 & 36.6 & 88.0 & \\
VBBr-K4.10 & 182.1 & 45.6 & 90.2 & [36] \\
VBBr-Ox3.10 & 195.5 & 16.1 & 85.3 & [37] \\
VBBr-Ox4.10 & 191.8 & 25.2 & & \\
Lewatit TP 207 & 80 & & & \\
Amberlyst 15 & 150 & & & \\
\hline
\end{tabular}

$\mathrm{T}_{\text {onset }}$-temperature of decomposition of polymers determined from TG measurements. Hp ${ }^{* *}$-heat of solvent evaporation determined from DSC thermograms. Tp $\mathrm{p}^{* *}$ - the temperature at the maximum of heat evaporation peak determined from DSC thermograms.

The research carried out using the differential scanning calorimetry (DSC) confirmed the relationship of the first stage of the decomposition of the synthesized sorbents with the evaporation of the residual solvents. The heat of this transition was calculated from thermograms (example DSC thermogram is shown in Figure S1), and the results are presented in Table 2. The amount of absorbed solvent by the VBBr sorbents increases after modification, while for the VBC sorbents, it practically did not change. Such a solvent absorption may be related to the sorption capacity of the polymer matrix. Characteristic temperatures related to phase transitions of polymers are not observed due to their crosslinked structure.

\subsection{Sorption Studies}

\subsubsection{Effect of $\mathrm{pH}$}

The $\mathrm{pH}$ of the solution is one of the most important parameters influencing adsorption and removal of metal ions from the aqueous feed solution. The percent of metals removal as a function of $\mathrm{pH}$ were plotted for all tested metals and illustrated in Figure 5a-d. The presented experimental data show that, regardless of the tested sorbents and the type of metal ions adsorbed, the sorption almost does not occur when the $\mathrm{pH}$ is lower than 2 . The sorption from solution with $\mathrm{pH}$ of 3 is much higher, but only for $\mathrm{Cd}(\mathrm{II})$ sorption onto VBC-K3.10 and VBBr-K3.10 as well as for the Cd(II) and $\mathrm{Cu}$ (II) sorption onto VBBr-K4.10, VBC-Ox3.10, VBC-Ox4.10, VBBr-Ox3.10, and VBBr-Ox4.10, in which the removal is higher than $50 \%$. Moreover, for the Cd(II) sorption onto VBC-K3.10, $\mathrm{VBBr}-\mathrm{K} 3.10, \mathrm{VBBr}-\mathrm{K} 4.10$, VBC-Ox3.10, VBC-Ox4.10, VBBr-Ox3.10, and VBBr-Ox4.10, the further increase in the $\mathrm{pH}$ value does not significantly affect the sorption efficiency. The most efficient metal ion removal from $\mathrm{pH}$ above 4 may be attributed to the fact that the positive species $\left(\mathrm{M}^{+2}\right)$ is the most abundant at this condition and can be attracted by an interaction with the negative 
zeta potential surface, which is in agreement with the electro-kinetic profile of the sorbents (see Figure S2). From the zeta potential measurements, a positive potential below a $\mathrm{pH}$ of 3.0-3.8 was indicated, which changed to a value negative above the isoelectric point.
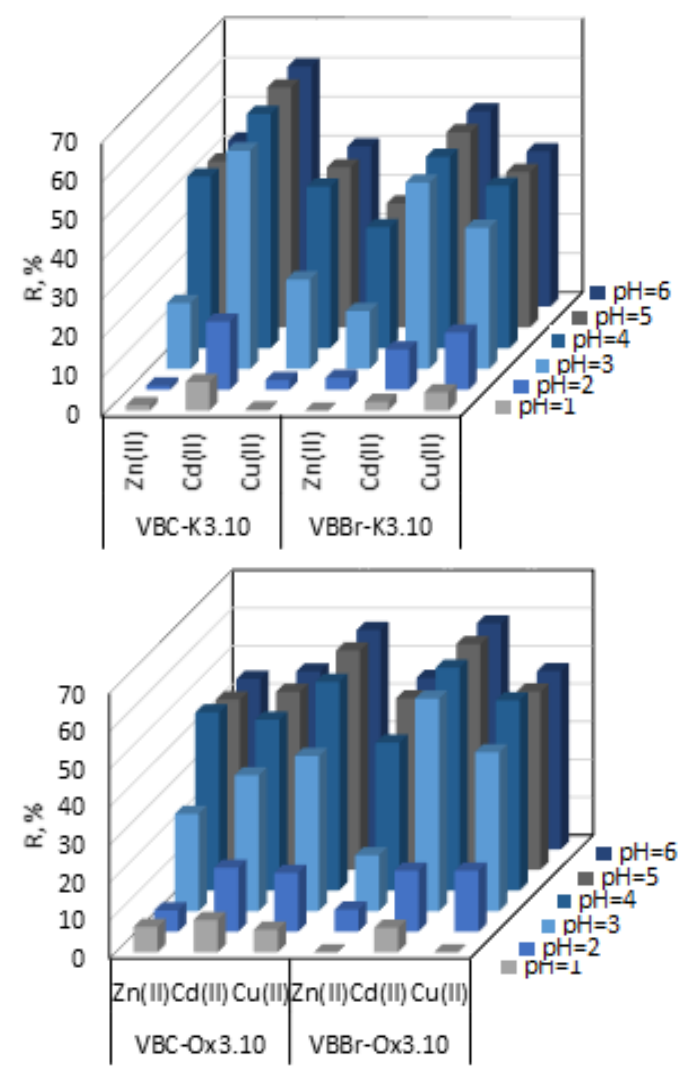
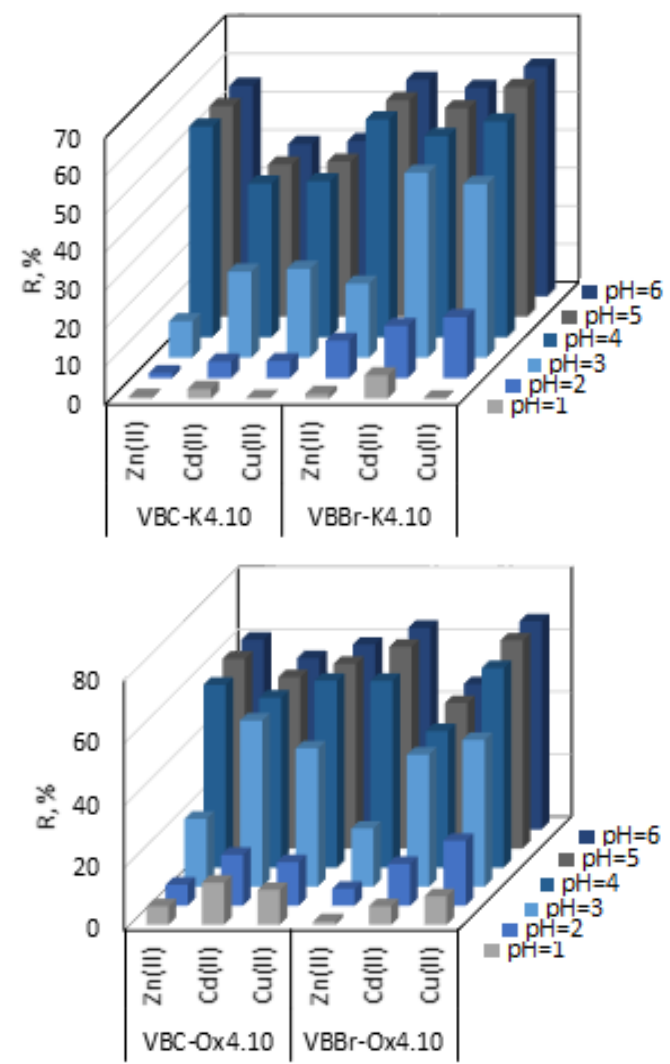

Figure 5. Effect of $\mathrm{pH}$ on $\mathrm{Pb}(\mathrm{II}), \mathrm{Cd}(\mathrm{II})$, and $\mathrm{Zn}(\mathrm{II})$ sorption with sorbent series $\mathrm{VBC}$ and $\mathrm{VBBr}(\mathrm{M}(\mathrm{II})=50 \mathrm{mg} / \mathrm{L}, \mathrm{pH}=1-6$, time-180 $\mathrm{min}$, sorbent dosage $-0.1 \mathrm{~g}$, and $\mathrm{V}-100 \mathrm{~mL}$ ).

The sorption results also indicate that the effectiveness of the process depends on the type and the structure of the functional group. For $\mathrm{Zn}(\mathrm{II})$ and $\mathrm{Cu}(\mathrm{II}), \mathrm{VBBr}-\mathrm{Ox} 4.10$ is much more efficient than other considered materials, while for $\mathrm{Cd}$ (II) the VBC-K3.10, resin has been found to be highly effective.

The dependence of the removal efficiency on the $\mathrm{pH}$ of the aqueous phase probably is a result of the competitive adsorption effect of the $\mathrm{H}^{+}$ions. This effect and speciation analysis [38] point to sorption of cationic species of $\mathrm{Zn}(\mathrm{II}), \mathrm{Cu}(\mathrm{II})$, and $\mathrm{Cd}(\mathrm{II})$ through interactions with the ketone group (through the lone pair of the donor carbonyl oxygen atom interaction) [39] or with the oxime group, which can bind a metal cation via oxygen and nitrogen atoms [40]. To further explore the interactions between metals cations and the appropriate groups, XPS measurement was employed. It was shown that, in the case of the ketone sorbents and the O1s emission, a new low-energy feature at $531.0 \mathrm{eV}$ appeared with the simultaneously decrease in $532.3 \mathrm{eV}$. The growth of the new feature also resulted in the growth of C 1s emissions at 284.8 and a decrease at $286.4 \mathrm{eV}$. For VBC and VBBr modified by the oxime derivatives, the appearance of new emission was also observed for $\mathrm{N}$ 1s $(399.4 \mathrm{eV})$, and growth emission at $402.26 \mathrm{eV}$. Both signals were consistent with the presence of $-\mathrm{H}-$ and the quaternary $\mathrm{N}$, in the resin structure.

\subsubsection{Effect of Time}

The time of contact of sorbents and aqueous feed solutions can influence the efficiency of metals removal. In this study, the effect of contact time was studied by making contact with both phases for 1-180 min. The results obtained indicate that, regardless of the structure of the functionalities, the metal sorption is very fast and equilibrium is reached 
after $10 \mathrm{~min}$. As shown in Figure 6, the sorption of $\mathrm{Zn}(\mathrm{II})$ with VBC-K3.10 is much faster than that observed for other sorbents: 1 min of shaking is enough to achieve equilibrium. In the case of other materials, the results have shown no influence of the functional group structure on the sorption rate.

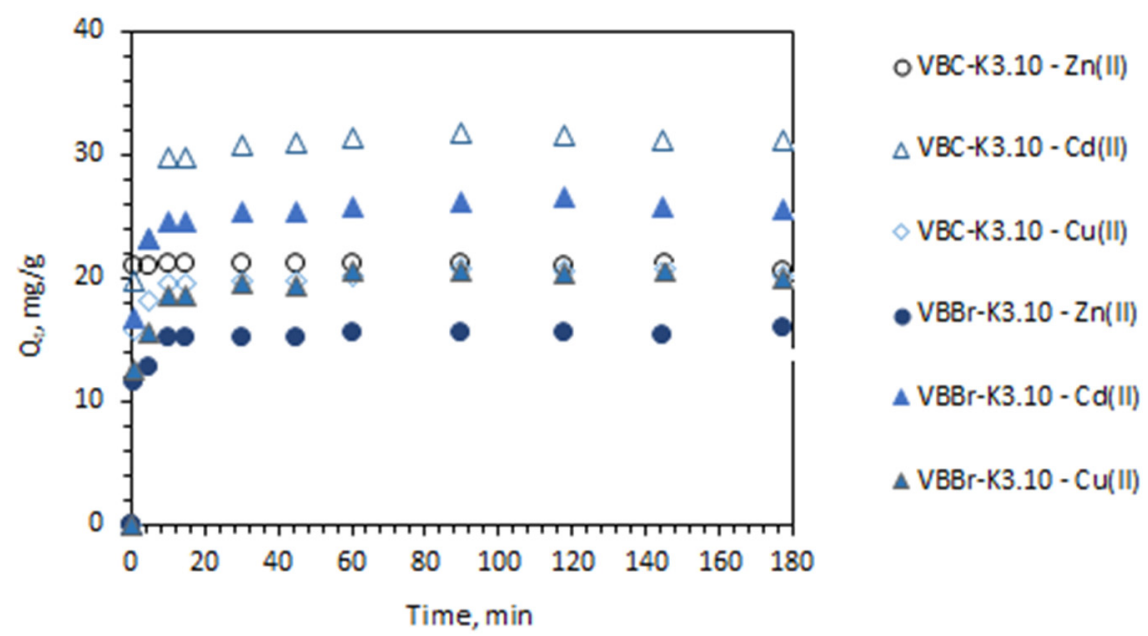

Figure 6. Effect of shaking time on $\mathrm{Cu}(\mathrm{II}), \mathrm{Cd}(\mathrm{II})$, and $\mathrm{Zn}(\mathrm{II})$ sorption with VBC-K3.10 and VBBr-K3.10 $(\mathrm{M}(\mathrm{II})=50 \mathrm{mg} / \mathrm{L}, \mathrm{pH}=5$, time: $1-180 \mathrm{~min}$, sorbent dosage $-0.1 \mathrm{~g}$, and $\mathrm{V}-100 \mathrm{~mL})$.

To analyze the sorption kinetics, the experimental data were fitted by using the selected models (pseudo-first order, pseudo-second order, intra-particle diffusion, and Elovich models). The fitting results such as kinetic rate constants, correlation coefficients, and $\mathrm{q}_{\mathrm{e}}$ are presented in Table 3 . The results unequivocally show that the pseudo-secondorder model describes the kinetics. The coefficient of determination value achieved varied from 0.999 to 1.000 , and the calculated values of $\mathrm{q}_{\mathrm{e}}$ were consistent with the experimental results. These results suggest that the rate-determining step is dominated by chemical sorption. In the case of the VBC-K3.10 sorbent, the values of the reaction rate constant $\mathrm{k}_{2}$ increase from 0.029 , and 0.056 to $1.362 \mathrm{~g} / \mathrm{mg} \cdot \mathrm{min}$ for $\mathrm{Zn}(\mathrm{II}), \mathrm{Cd}(\mathrm{II})$, and $\mathrm{Cu}(\mathrm{II})$, respectively. In the case of the VBBr-K3.10 sorbent, the values of $\mathrm{k}_{2}$ rise in order $\mathrm{Zn}$ (II) $>\mathrm{Cd}$ (II) $>\mathrm{Cu}$ (II) $(0.072,0.056$, and $0.029 \mathrm{~g} / \mathrm{mg} \cdot \mathrm{min}$, respectively)

Table 3. Kinetic parameters of $\mathrm{Cu}(\mathrm{II})$, Cd(II), and Zn(II) sorption with VBC-K3.10 and VBBr-K3.10.

\begin{tabular}{|c|c|c|c|c|c|c|}
\hline \multirow{2}{*}{ Kinetic Model } & \multicolumn{3}{|c|}{ VBC-K3.10 } & \multicolumn{3}{|c|}{ VBBr-K3.10 } \\
\hline & $\mathrm{Cu}(\mathrm{II})$ & Cd(II) & $\mathrm{Zn}(\mathrm{II})$ & $\mathrm{Cu}(\mathrm{II})$ & Cd(II) & $\mathrm{Zn}(\mathrm{II})$ \\
\hline $\mathrm{q}_{\exp }(\mathrm{mg} / \mathrm{g})$ & 20.8 & 31.9 & 21.4 & 20.9 & 26.2 & 15.9 \\
\hline \multicolumn{7}{|c|}{ Pseudo-first order } \\
\hline $\mathrm{k}_{1\left(\min ^{-1}\right)}$ & 0.028 & 0.035 & 0.015 & 0.029 & 0.033 & 0.023 \\
\hline $\mathrm{q}_{\mathrm{e} . \mathrm{cal}}(\mathrm{mg} / \mathrm{g})$ & 20.8 & 31.9 & 21.3 & 20.9 & 26.2 & 15.9 \\
\hline$R^{2}$ & 0.915 & 0.913 & 0.667 & 0.954 & 0.804 & 0.854 \\
\hline \multicolumn{7}{|c|}{ Pseudo-second order } \\
\hline $\mathrm{k}_{2}(\mathrm{~g} / \mathrm{mg} \min )$ & 0.056 & 0.029 & 1.362 & 0.032 & 0.056 & 0.072 \\
\hline $\mathrm{q}_{\mathrm{e}}(\mathrm{mg} / \mathrm{g})$ & 20.7 & 32.1 & 21.4 & 20.8 & 26.2 & 15.9 \\
\hline$R^{2}$ & 0.999 & 0.999 & 1.00 & 0.999 & 0.999 & 0.999 \\
\hline \multicolumn{7}{|c|}{ Intra-particle diffusion } \\
\hline $\mathrm{k}_{\mathrm{ip} 2}\left(\mathrm{mg} / \mathrm{g} \min ^{0.5}\right)$ & 1.18 & 2.12 & 0.99 & 1.37 & 1.61 & 0.95 \\
\hline C & 10.9 & 14.2 & 13.6 & 9.1 & 12.9 & 7.9 \\
\hline $\mathrm{R}^{2}$ & 0.763 & 0.723 & 0.997 & 0.781 & 0.604 & 0.997 \\
\hline \multicolumn{7}{|c|}{ Elovich } \\
\hline$\alpha(\mathrm{mg} / \mathrm{g} \min )$ & 106.3 & 61.7 & 660.5 & 39.3 & 76.4 & 59.32 \\
\hline$\beta(\mathrm{g} / \mathrm{mg})$ & 0.376 & 0.208 & 0.450 & 0.325 & 0.271 & 0.469 \\
\hline $\mathrm{R}^{2}$ & 0.954 & 0.925 & 0.926 & 0.965 & 0.863 & 0.926 \\
\hline
\end{tabular}




\subsubsection{Effect of Metals Ions Concentration}

The influence of the initial metal ion concentration on their removal with the sorbent series VBC and VBBr was also investigated. The experiments were conducted for $3 \mathrm{~h}$ of shaking at a $\mathrm{pH}$ of 5 ; at $\mathrm{T}=298.15 \mathrm{~K}$; and using the aqueous feed solution containing from 50 to $200 \mathrm{mg} / \mathrm{L}$ of $\mathrm{Cu}(\mathrm{II}), \mathrm{Cd}(\mathrm{II})$, and $\mathrm{Zn}$ (II). From the results presented ion Figure 7, it can be seen that the removal of metals ions is strongly dependent on their initial concentration in the water phase and on the structure of the pyridinium group located on the sorbents surface.

\section{$\mathrm{Cu}(\mathrm{II})$}
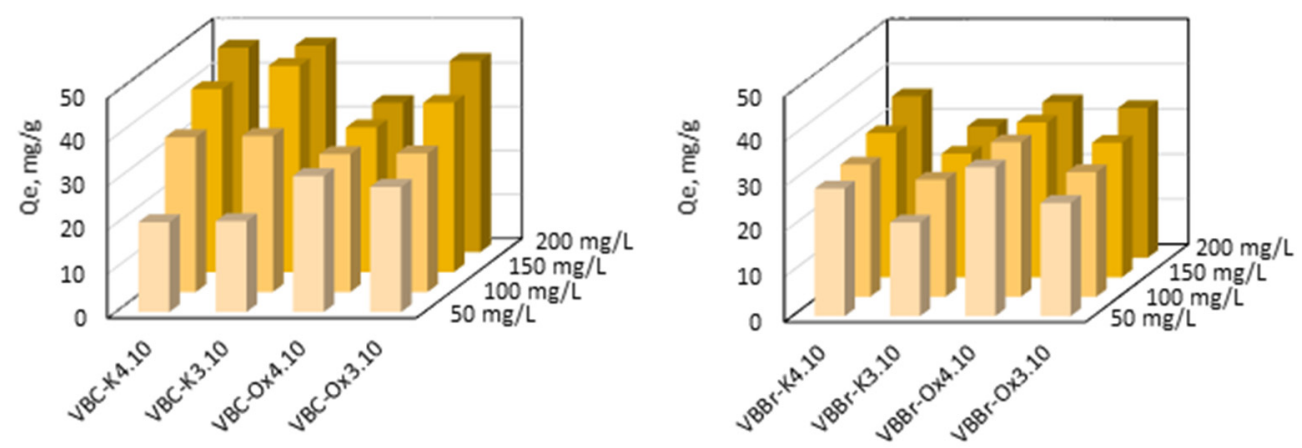

\section{Cd(II)}
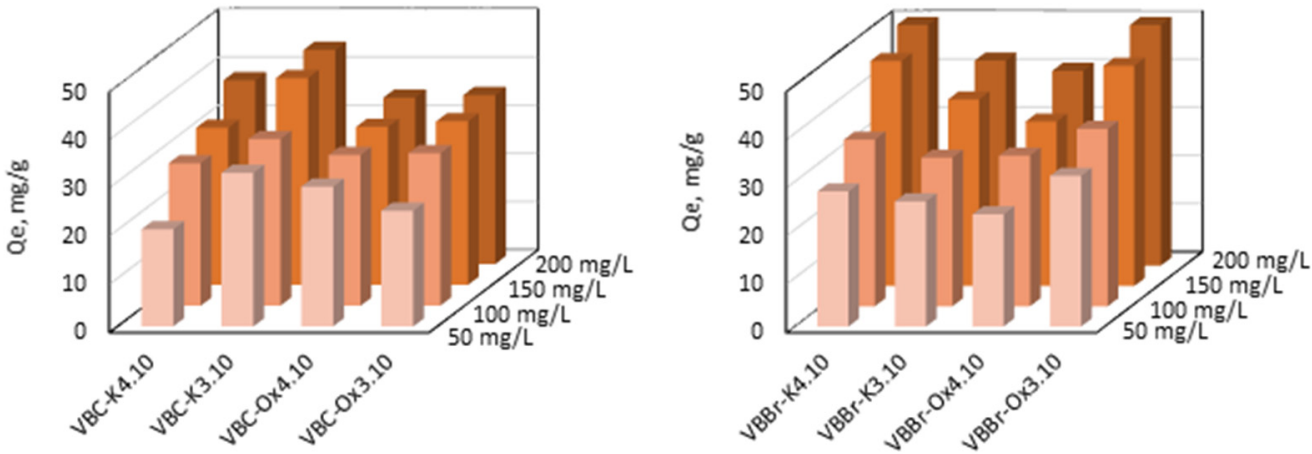

$\mathrm{Zn}(\mathrm{II})$
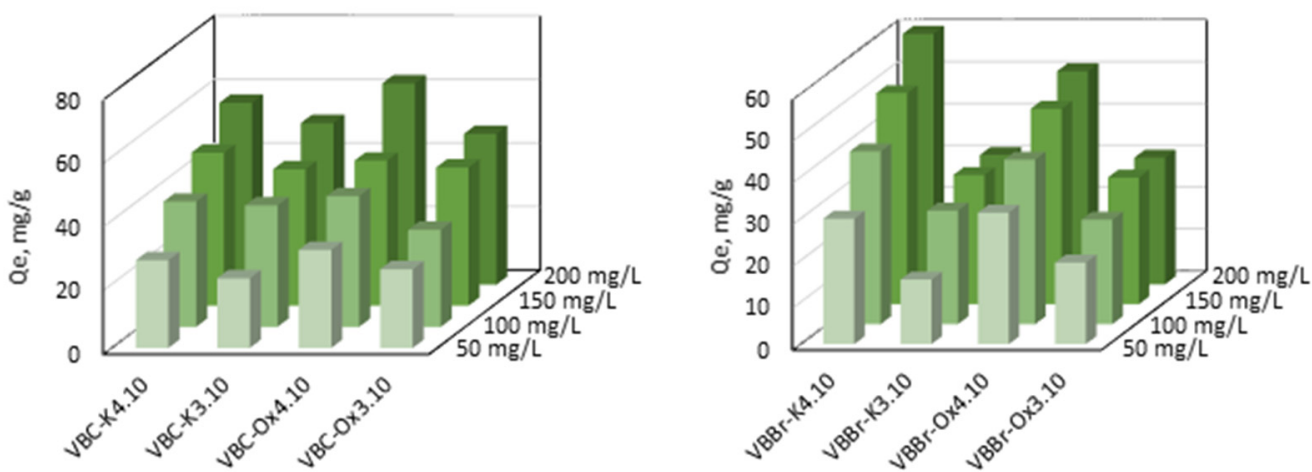

Figure 7. Effect of initial concentration of $\mathrm{Cu}(\mathrm{II}), \mathrm{Cd}(\mathrm{II})$, and $\mathrm{Zn}(\mathrm{II})$ on their sorption with $\mathrm{VBC}$ and VBBr series sorbents $(\mathrm{M}(\mathrm{II})=50-200 \mathrm{mg} / \mathrm{L}, \mathrm{pH}=5$, time: $180 \mathrm{~min}$, sorbent dosage $-0.1 \mathrm{~g}$, and $\mathrm{V}-100 \mathrm{~mL})$.

In the case of the $\mathrm{Cu}(\mathrm{II})$ sorption and almost all sorbent series $\mathrm{VBC}$, the metal ions removal increases with the increase in the initial $\mathrm{Cu}$ (II) concentration but without saturation achieving. Only for VBC-Ox4.10, the increase is insignificant $\left(\mathrm{Q}_{\mathrm{e}}\right.$ increases from 31 to $34 \mathrm{mg} / \mathrm{g}$ using the aqueous feed solutions at 50 and $200 \mathrm{mg} / \mathrm{L}$, respectively), which suggests that $Q_{e}=34 \mathrm{mg} / \mathrm{g}$ is the maximum loading. An insignificant increase in the $Q_{e}$ value is also observed using VBC-K3.10 as the sorbent and the aqueous feed solutions 
containing 150 and $200 \mathrm{mg} / \mathrm{L}$ of $\mathrm{Cu}(\mathrm{II})$. In this case, the results indicate that the value $47 \mathrm{mg} / \mathrm{g}$ is slightly off the saturation level. The sorbent series VBBr shows much worse sorption properties towards copper(II). Additionally, the use of aqueous solutions with increasing metal ion concentrations indicates low saturation. The studied sorbents behave differently in contact with the water phase containing cadmium ions. The VBBr series sorbents show much better sorption properties than the VBC series sorbents. For example, $1 \mathrm{~g}$ of $\mathrm{VBBr}-\mathrm{K} 4.10$ removes $52 \mathrm{mg}$ of $\mathrm{Cd}(\mathrm{II})$, while $\mathrm{VBC}-\mathrm{K} 4.10$ only removes $38 \mathrm{mg}$. A similar effect is observed for $\mathrm{VBBr}-\mathrm{O} \times 3.10$ and $\mathrm{VBCl}-\mathrm{O} \times 3.10$ (53 and $35 \mathrm{mg} / \mathrm{g}$, respectively). Moreover, in the case of the VBC sorbents, only VBC-K3.10 removes more Cd(II) than $40 \mathrm{mg} / \mathrm{g}$.

The sorption of $\mathrm{Zn}$ (II) did not show more significant differences between the sorbents of the $\mathrm{VBC}$ and the $\mathrm{VBBr}$ series than that observed for $\mathrm{Cu}(\mathrm{II})$ and $\mathrm{Cd}(\mathrm{II})$. In the case of the series VBC, zinc(II) can be removed in $63 \mathrm{mg} / \mathrm{g}$ (VBC-Ox4.10), while in the case of the $\mathrm{VBBr}$ series, zinc(II) can be removed in $60 \mathrm{mg} / \mathrm{g}$ (VBBr-K4.10). However, comparing the structure of the functional group located on the surface of the VBC or VBBr matrix, the differences can be observed. The modification with $\mathrm{K} 4.10$ was much better with VBBr-K4.10, while the modification with K3.10 was much better with VBC-K3.10. Am opposite relationship can be observed when comparing sorbents VBC-Ox3.10 and VBBr-Ox3.10 as well as VBC-Ox4.10 and VBBr-Ox4.10. The sorbent series VBC is much more efficient than the sorbent series VBBr.

The above experimental data were also fitted to four isothermal models: Freundlich, Langmuir, Dubinin-Radushkevich, and Temkin. Modelling is necessary for the determination of the sorption mechanism and to predict the effectiveness of the sorption system. The isotherm parameters are summarized in Tables S2 and S3. The correlation coefficients indicate that the Langmuir model fits the data better than other considered models (for the VBC series, $\mathrm{R}^{2}$ varies from 0.995 to 1.000 , while for the $\mathrm{VBBr}$ series, the $\mathrm{R}^{2}$ values vary from 0.992 to 0.999 ). Fitting the Langmuir isotherm model indicates that sorption takes place on a homogeneous surface as a result of complexation (coordination or ion exchange mechanisms). In such a process, metal ions are adsorbed in the form of a monolayer and no interactions between the adsorbate are observed. The equilibrium constant $R_{L}$ has also been calculated, and for almost all tested sorbents, the values for each metals sorption are between 0 and 1 , indicating the adsorption as favorable. Only for the $\mathrm{Cu}$ (II) sorption onto the $\mathrm{VBBr}-\mathrm{Ox} 4.10$ surface is $\mathrm{R}_{\mathrm{L}}$ equal 0 , which indicates an irreversible process. A very good fit has also been noted for the Temkin model $\left(R^{2}=0.991-0.998\right)$, especially in the case of the $\mathrm{Cu}(\mathrm{II})$ and $\mathrm{Zn}$ (II) sorption onto VBC-K3.10; the $\mathrm{Cu}(\mathrm{II}), \mathrm{Cd}(\mathrm{II})$, and $\mathrm{Zn}(\mathrm{II})$ sorption onto VBC-K4.10; the Cd(II) sorption onto VBBr-K4.10, VBBr-Ox3.10, and VBBr-Ox4.10; as well as the $\mathrm{Zn}$ (II) sorption onto VBC-Ox4.10. Fitting the Temkin isotherm model also confirms that the adsorption of the demonstrated systems follows a chemisorption process.

The estimated adsorption abilities were also compared with the sorption properties of strongly acidic (Amberlite IR 120) and weakly acidic (Lewatit CNP 80) ion-exchange resins as well as with the latest tested composites poly (ethyleneimine)-silica gels and poly (amidoamine)-graphene oxide and with xanthan-modified magnetic chitosan (see Table 4). It can be seen that, compared with most of the sorbents mentioned, VBC-K3.10 has a greater adsorption capacity in relation to $\mathrm{Cu}(\mathrm{II}), \mathrm{Cd}(\mathrm{II})$, and $\mathrm{Zn}$ (II). Only Amberlite IR 120 shows much stronger properties in relation to $\mathrm{Cd}(\mathrm{II})$. The strong adsorption capacity of Amberlite IR 120 can be attributed to its strong interaction and to the process being carried out at a $\mathrm{pH}$ above 6, which for $\mathrm{Cu}(\mathrm{II}), \mathrm{Zn}(\mathrm{II})$, and $\mathrm{Cd}(\mathrm{II})$ resulted not only in the metal-resin interaction but also in the precipitation of hydroxides. 
Table 4. Comparison of capacities towards $\mathrm{Cu}(\mathrm{II}), \mathrm{Cd}(\mathrm{II})$, and $\mathrm{Zn}(\mathrm{II})$ of the selected adsorbents.

\begin{tabular}{ccccc}
\hline \multirow{2}{*}{ Adsorbent } & \multicolumn{3}{c}{ Adsorption Capacity, mg/g } & \multirow{2}{*}{ Ref. } \\
\cline { 2 - 4 } & Cu(II) & Cd(II) & Zn(II) & \\
\hline Amberlite IR 120 & 21.9 & 101.0 & 85.0 & {$[41]$} \\
Lewatit CNP 80 & 10.2 & 4.9 & 20.3 & {$[42]$} \\
poly(ethyleneimine)-silica gels & 38.5 & - & 52.1 & {$[43]$} \\
poly(amidoamine)-graphene oxide & 8.7 & - & 13.2 & {$[43]$} \\
xanthate-modified magnetic chitosan & 34.5 & 55.0 & 20.8 & {$[44,45]$} \\
VBC-K3.10 & 68.6 & 47.6 & 72.3 & This work \\
\hline
\end{tabular}

\subsubsection{Effect of Temperature}

The temperature at which the sorption process is carried out can influence the removal of the metals ions. Therefore, in these studies, that effect was also considered. A series of experiments were performed at temperatures of 25,35 and $45^{\circ} \mathrm{C}$; at a constant $\mathrm{pH}$ value of 5; and at the constant metal ion concentration of $100 \mathrm{mg} / \mathrm{L}$. The results obtained are presented in Figure 8.

\section{$\mathrm{Cu}(\mathrm{II})$}
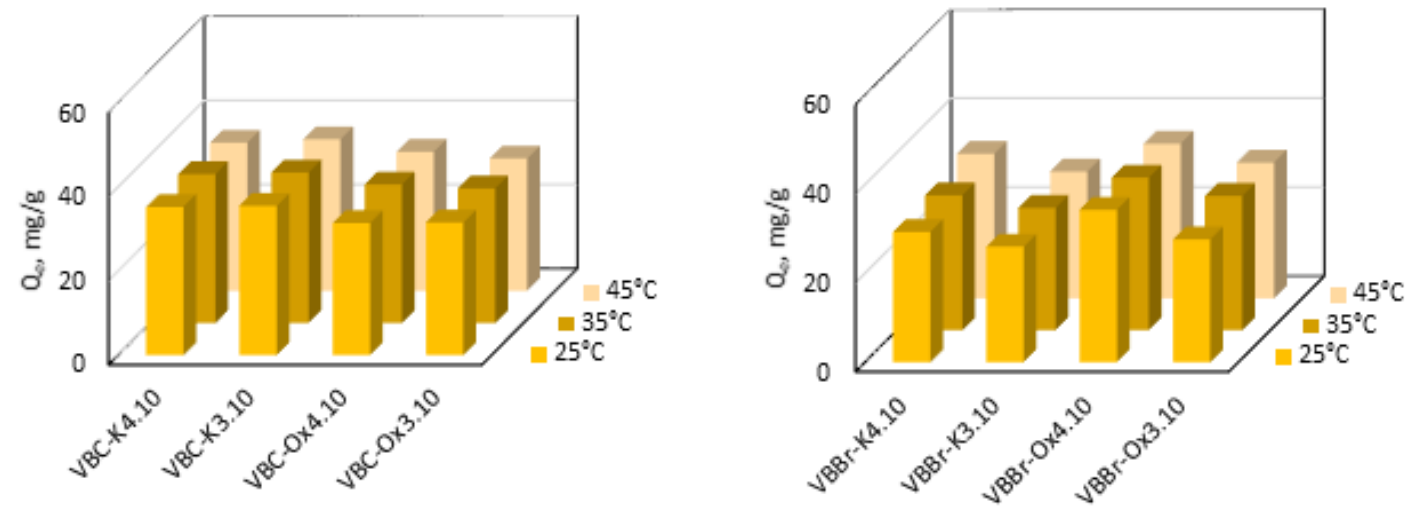

\section{$\mathrm{Cd}(\mathrm{II})$}
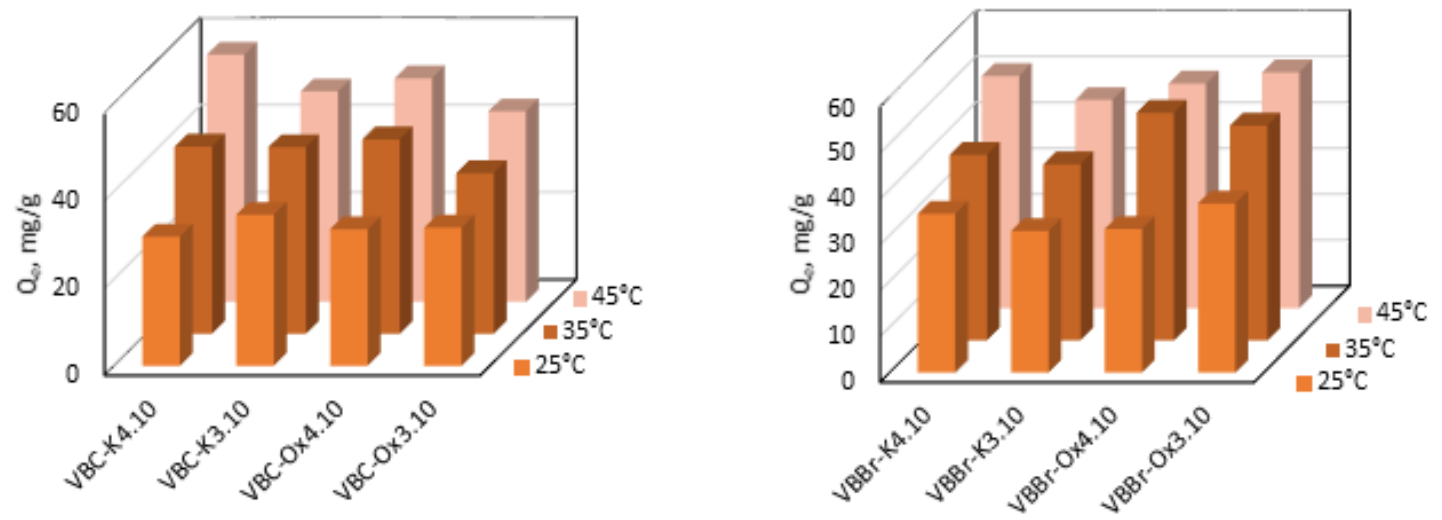

Figure 8. Cont. 


\section{$\mathrm{Zn}(\mathrm{II})$}
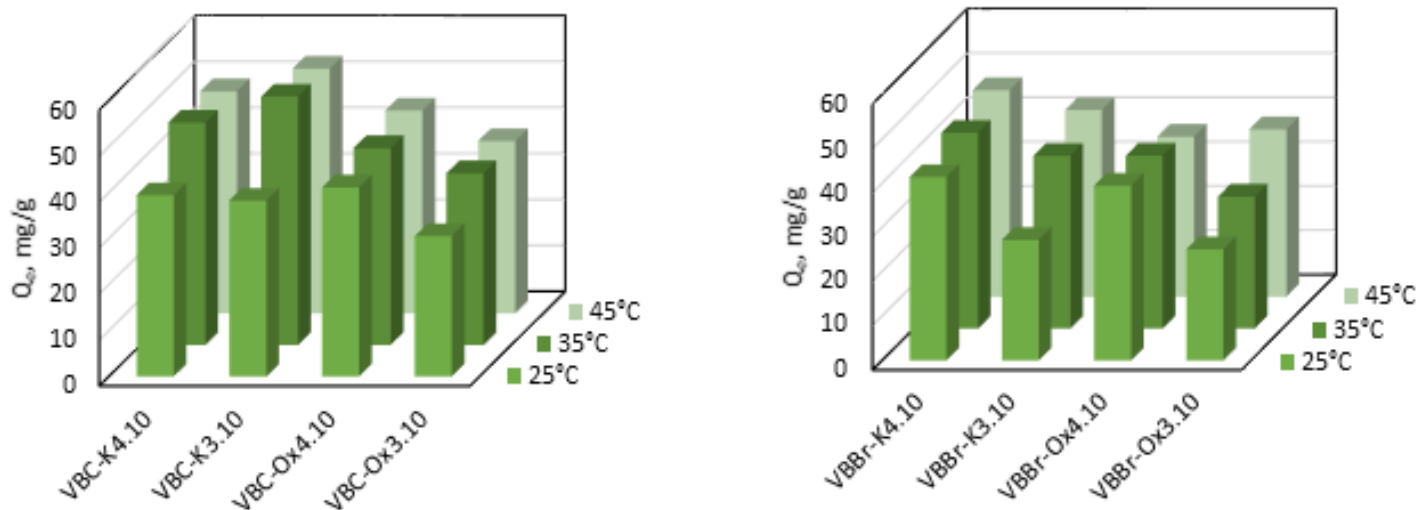

Figure 8. Effect of temperature on $\mathrm{Cu}(\mathrm{II}), \mathrm{Cd}(\mathrm{II})$, and $\mathrm{Zn}(\mathrm{II})$ sorption with $\mathrm{VBC}$ and $\mathrm{VBBr}$ series sorbents $(\mathrm{M}(\mathrm{II})=100 \mathrm{mg} / \mathrm{L}$, $\mathrm{pH}=5$, time: $180 \mathrm{~min}$, sorbent dosage $-0.1 \mathrm{~g}$, and $\mathrm{V}-100 \mathrm{~mL}$ ).

From the presented results, it can be concluded that the sorption of $\mathrm{Cu}$ (II) does not change remarkably with the change in temperature. A similar effect is observed for the $\mathrm{Zn}$ (II) sorption with the sorbents obtained by the modification with Ox4.10. In contrast, in the case of the $\mathrm{Cd}(\mathrm{II})$ sorption and other $\mathrm{Zn}(\mathrm{II})-\mathrm{VBC}$ and $\mathrm{Zn}(\mathrm{II})-\mathrm{VBBr}$ systems, the increase in temperature makes the sorbents more efficient. The effect is significant when using the $\mathrm{VBC}$ and $\mathrm{VBBr}$ series materials as sorbents of Cd(II). For instance, the sorption of Cd(II) with VBC-K3.10 increases by almost $100 \%$ if the temperature is changed from 25 to $45^{\circ} \mathrm{C}$. In the case of the zinc(II) sorption, the effect is particularly evident using the $\mathrm{VBBr}-\mathrm{K} 3.10$ and VBBr-Ox3.10 resins, which were found as the least efficient sorbents of $\mathrm{Zn}$ (II). The increase in the sorption may result from the increased diffusion rate of the adsorbate ions through the surface boundary layer, especially if the hydrophobic nature of the surface was found. This increase may also be due to changes in the availability of the active sites capable of coordinating with the metal ions. Here, the temperature can cause isomerization changes in the oxime $\mathrm{C}=\mathrm{N}$ or conformational changes in the decile chain.

\subsection{Reusability Test}

The sorbent application potential is influenced not only by the sorption capacity or the kinetics of the process but also by the desorption of the adsorbed component with the participation of relatively mild reagents. Therefore, experiments were also carried out in order to develop the most optimal desorbing agent. This agent not only should easily desorb the metal ions but also should enable sorption immediately after regeneration in subsequent cycles of the process. After sorption (100 mg/L Cu(II), Cd(II), or $\mathrm{Zn}$ (II) at a $\mathrm{pH}$ of 5 and at a temperature of $45^{\circ} \mathrm{C}$ ), the $1 \mathrm{~g}$ of sorbents (VBC-K3.10 and VBBr-K3.10) were contacted with $10 \mathrm{~mL}$ of 0.1 and $0.01 \mathrm{M} \mathrm{HCl}$ and with a $0.5 \mathrm{M}$ solution of $\mathrm{NaCl}$ and $\mathrm{Na}_{2} \mathrm{SO}_{4}$. Immediately after desorption, the separated sorbent was contacted with the fresh aqueous feed solution. The sorption-desorption cycle was repeated five times.

The obtained results indicated that, regardless of the sorbent used and the metals ions removed, the desorption of the metals with the salts solutions was not very efficient (desorption with the $\mathrm{NaCl}$ solution ranged from 41 to $59 \%$, while using the $\mathrm{Na}_{2} \mathrm{SO}_{4}$ solution, it ranged from 52 to $64 \%)$. Slightly better results were obtained using $0.01 \mathrm{M} \mathrm{HCl}(58-72 \%)$, but the $0.1 \mathrm{M}$ $\mathrm{HCl}$ solution was found to be the most efficient desorbing agent. The results also showed that five-fold repetition of the sorption-desorption procedure using the $0.1 \mathrm{M} \mathrm{HCl}$ solution as the desorbing agent did not adversely affect the adsorption properties of VBC-K3.10 and VBBr-K3.10 (the differences in the removal efficiency were 5-7\% and 4-8\%, respectively). 


\section{Conclusions}

Based on the conducted research, it was shown that the proposed procedure of the copolymer of vinylbenzyl chloride and divinylbenzene modification through quaternization in toluene as well as halogen exchange according the $S_{N} 2$ mechanism (poly(vinylbenzyl bromide-co-divinylbenzene) synthesis) enabled us to obtain novel ionic liquid-imprinted polymer sorbents. The sorption studies clearly show that the sorption properties depended not only on the type of metals ions and on the functional group structure (ketone or oxime substituent located at 3- or 4-position in pyridine ring as well as chloride or bromide counter ion for pyridinium nitrogen) but also on the $\mathrm{pH}$, temperature, and initial concentration of metal ions. Both $\mathrm{pH}$ as well as temperature sorption increases with the increase in values of the parameters. The $\mathrm{pH}$ dependence indicated the sorption of cationic forms of metals, which at a $\mathrm{pH}$ below 2 competed with free $\mathrm{H}^{+}$. This effect also indicated the ease of desorption, e.g., with diluted acid. The temperature effect indicated that the process was exothermic or that the increased temperature increased the availability of the active centers capable of coordinating to the metals ions. This indicated, in conjunction with thermogravimetric analysis, a high sorption potential of the resins at higher temperatures than $25^{\circ} \mathrm{C}$. The results obtained also showed that, regardless of the structure of the functionalities, the metal sorption was very fast and equilibrium was reached even within $1 \mathrm{~min}$ of shaking. The fitting to the selected isotherm models indicated that sorption takes place on the homogeneous surface as a result of complexation (coordination by the imine moiety or the oxime $\mathrm{OH}$ ). Among the selected compounds, there was none that turned out to be the most effective for all absorbed metal ions, e.g., for $\mathrm{Zn}$ (II) sorption, the most efficient was VBC-Ox4.10 (84 mg/g); for Cd(II) sorption, the most efficient was VBBr-Ox3.10 (63 mg/g); and for $\mathrm{Cu}$ (II) sorption, the most efficient was VBC-K3.10 (69 mg/g). Moreover, the possibility of reusing the sorbent allowed us to state that these materials could be successfully used for $\mathrm{Cu}(\mathrm{II}), \mathrm{Cd}(\mathrm{II})$, and $\mathrm{Zn}(\mathrm{II})$ removal.

Supplementary Materials: The following are available online at https://www.mdpi.com/article/10 $.3390 / \mathrm{ma14175008/s1,} \mathrm{Figure} \mathrm{S1:} \mathrm{DSC} \mathrm{thermogram} \mathrm{of} \mathrm{the} \mathrm{VBBr-Ox3.10} \mathrm{sorbent,} \mathrm{Figure} \mathrm{S2:} \mathrm{Values}$ of the zeta potential measured as a function of $\mathrm{pH}$, Table S1. Values of the isoelectric point and contact angle of fabricated sorbent series VBC and VBBr, Table S2: Isotherms parameters of different models for the sorption of $\mathrm{Cu}(\mathrm{II}), \mathrm{Zn}(\mathrm{II})$, and $\mathrm{Cd}(\mathrm{II})$ onto $\mathrm{VBC}-\mathrm{K} 3.10, \mathrm{VBBr}-\mathrm{K} 3.10, \mathrm{VBC}-\mathrm{K} 4.10$, and VBBr-K4.10, Table S3: The isotherm parameters of different models for the sorption of $\mathrm{Cu}(\mathrm{II}), \mathrm{Zn}(\mathrm{II})$, and Cd(II) onto VBC-Ox3.10, VBBr-Ox3.10, VBC-Ox4.10, and VBBr-Ox4.10.

Author Contributions: Conceptualization, K.W.; methodology, K.W., T.B., M.N. and A.M.; investigation, K.W., P.D., K.F., T.B., M.N., A.L. and A.M.; formal analysis and writing-original draft preparation, K.W., P.D., T.B., M.N. and A.M.; writing-review and editing, K.W.; visualization, K.W., K.F., T.B., M.N., A.L. and A.M.; supervision and funding acquisition, K.W. All authors have read and agreed to the published version of the manuscript.

Funding: This work was financed by the National Science Centre (Poland) (grant No. 2017/27/B/ST8/01484).

Institutional Review Board Statement: Not applicable.

Informed Consent Statement: Not applicable.

Data Availability Statement: Not applicable.

Acknowledgments: The authors thank the funding institution for support.

Conflicts of Interest: The authors declare no conflict of interest.

\section{References}

1. Gandhi, S.M.; Sarkar, B.C. Metals and Minerals: Global Trends, Outlook, and Mineral Exploration. Essent. Miner. Explor. Eval. 2016, 1-21. [CrossRef]

2. Xiong, C.; Zheng, Y.; Feng, Y.; Yao, C.; Ma, C.; Zheng, X.; Jiang, J. Preparation of a novel chloromethylated polystyrene-2-amino1,3,4-thiadiazole chelating resin and its adsorption properties and mechanism for separation and recovery of Pt(IV) from aqueous solutions. J. Mater. Chem. A 2014, 2, 5379-5386. [CrossRef] 
3. Huang, H.; Wang, Y.; Zhang, Y.; Niu, Z.; Li, X. Amino-functionalized graphene oxide for $\mathrm{Cr}(\mathrm{VI}), \mathrm{Cu}(\mathrm{II}), \mathrm{Pb}(\mathrm{II}) \mathrm{and} \mathrm{Cd}(\mathrm{II}) \mathrm{removal}$ from industrial wastewater. Open Chem. 2020, 18, 97-107. [CrossRef]

4. Khan, T.N.; Khan, F.R. Determination of Lead, Arsenic and Chromium Contents in Two Types of Mineral Trioxide Aggregate Using Atomic Absorption Spectrometry. J. Pak. Dent. Assoc. 2020, 29, 223-227. [CrossRef]

5. Li, Z.; Wang, Z.; Wang, C.; Ding, S.; Li, F.; Lin, H. Preparation of magnetic resin microspheres M-P(MMA-DVB-GMA) and the adsorption property to heavy metal ions. Appl. Surf. Sci. 2019, 496, 143708. [CrossRef]

6. Fatima, N.; Zhang, Q.; Chen, R.; Yan, D.; Zhou, Q.; Lu, X.; Xin, J. Adsorption Thermodynamics and Kinetics of Resin for Metal Impurities in Bis(2-hydroxyethyl) Terephthalate. Polymers 2020, 12, 2866. [CrossRef] [PubMed]

7. Zhou, H.; Zheng, J.; Wang, H.; Wang, J.; Song, X.; Cao, Y.; Fang, L.; Feng, Y.; Xiong, C. Preparation of a novel chloromethylated polystyrene-2-mercapto-1,3,4-thiadiazole chelating resin and its adsorption properties and mechanism for separation and recovery of $\mathrm{Hg}$ (II) from aqueous solutions. Water Sci. Technol. 2017, 76, 1915-1924. [CrossRef] [PubMed]

8. Rahman, N.; Nasir, M.; Varshney, P.; Al-Enizi, A.M.; Ubaidullah, M.; Shaikh, S.F.; Al-Adrabalnabi, M.A. Efficient removal of Pb(II) from water using silica gel functionalized with thiosalicylic acid: Response surface methodology for optimization. J. King Saud Univ. Sci. 2021, 33, 101232. [CrossRef]

9. Bali, M.; Tlili, H. Removal of heavy metals from wastewater using infiltration-percolation process and adsorption on activated carbon. Int. J. Environ. Sci. Technol. 2018, 16, 249-258. [CrossRef]

10. Kobayashi, Y.; Ogata, F.; Nakamura, T.; Kawasaki, N. Synthesis of novel zeolites produced from fly ash by hydrothermal treatment in alkaline solution and its evaluation as an adsorbent for heavy metal removal. J. Environ. Chem. Eng. 2020, 8, 103687. [CrossRef]

11. Jamshaid, A.; Hamid, A.; Muhammad, N.; Naseer, A.; Ghauri, M.; Iqbal, J.; Rafiq, S.; Shah, N.S. Cellulose-based Materials for the Removal of Heavy Metals from Wastewater-An Overview. ChemBioEng Rev. 2017, 4, 240-256. [CrossRef]

12. Han, D.; Row, K.H. Recent applications of ionic liquids in separation technology. Molecules 2010, 15, 2405-2426. [CrossRef] [PubMed]

13. Ho, T.D.; Canestraro, A.J.; Anderson, J.L. Ionic liquids in solid-phase microextraction: A review. Anal. Chim. Acta 2011, 695, 18-43. [CrossRef] [PubMed]

14. Fontanals, N.; Borrull, F.; Marcé, R.M. Ionic liquids in solid-phase extraction. TrAC Trends Anal. Chem. 2012, 41, 15-26. [CrossRef]

15. Quijada-Maldonado, E.; Olea, F.; Sepúlveda, R.; Castillo, J.; Cabezas, R.; Merlet, G.; Romero, J. Possibilities and challenges for ionic liquids in hydrometallurgy. Sep. Purif. Technol. 2020, 251, 117289. [CrossRef]

16. Zhang, Y.; Wang, H.; Sun, N.; Chi, R. Experimental and computational study on mechanism of dichromate adsorption by ionic liquid-bonded silica gel. Sep. Purif. Technol. 2018, 205, 84-93. [CrossRef]

17. Nkinahamira, F.; Su, T.; Xie, Y.; Ma, G.; Wang, H.; Li, J. High pressure adsorption of CO2 on MCM-41 grafted with quaternary ammonium ionic liquids. Chem. Eng. J. 2017, 326, 831-838. [CrossRef]

18. Mohamedali, M.; Ibrahim, H.; Henni, A. Imidazolium based ionic liquids confined into mesoporous silica MCM-41 and SBA-15 for carbon dioxide capture. Microporous Mesoporous Mater. 2020, 294, 109916. [CrossRef]

19. Liang, P.; Peng, L. Ionic liquid-modified silica as sorbent for preconcentration of cadmium prior to its determination by flame atomic absorption spectrometry in water samples. Talanta 2010, 81, 673-677. [CrossRef]

20. Saleem, S.; Saqib, A.N.S.; Mujahid, A.; Hanif, M.; Mustafa, G.; Mahmood, T.; Waseem, A.; Khan, A.R. Extraction of Pb(II) from water samples by ionic liquid-modified silica sorbents. New Pub. Balaban 2014, 52, 7915-7924. [CrossRef]

21. Malefetse, T.; Mamba, B.; Krause, R.; Mahlambi, M. Cyclodextrin-ionic liquid polyurethanes for application in drinking water treatment. Water SA 2009, 35, 729-734. [CrossRef]

22. Navarro, R.; Lira, M.A.; Saucedo, I.; Alatorre, A.; Guibal, E. Amberlite XAD-1180 impregnation with Cyphos IL101 for the selective recovery of precious metals from $\mathrm{HCl}$ solutions. Gold Bull. 2016, 50, 7-23. [CrossRef]

23. Navarro, R.; Lira, M.A.; Saucedo, I.; Alatorre, A.; Avila, M.; Guibal, E. Amberlite XAD Resins Impregnated with Ionic Liquids for $\mathrm{Au}(\mathrm{III})$ Recovery. Macromol. Symp. 2017, 374. [CrossRef]

24. Navarro, R.; Alba, J.; Saucedo, I.; Guibal, E. $\mathrm{Hg}$ (II) removal from $\mathrm{HCl}$ solutions using a tetraalkylphosphonium ionic liquid impregnated onto Amberlite XAD-7. J. Appl. Polym. Sci. 2014, 131. [CrossRef]

25. Navarro, R.; Saucedo, I.; Gallardo, V.; Guibal, E. Fe(III) recovery from HCl solutions using amberlite XAD-7 resin impregnated with a tetraalkyl phosphonium ionic liquid. Can. J. Chem. Eng. 2016, 94, 107-116. [CrossRef]

26. Wieszczycka, K.; Filipowiak, K.; Wojciechowska, I.; Buchwald, T. Efficient metals removal from waste pickling liquor using novel task specific ionic liquids-classical manner and encapsulation in polymer shell. Sep. Purif. Technol. 2021, 262, 118239. [CrossRef]

27. Wieszczycka, K.; Filipowiak, K.; Aksamitowski, P.; Wojciechowska, I. Task-specific ionic liquid impregnated resin for zinc(II) recovery from chloride solutions. J. Mol. Liq. 2020, 299. [CrossRef]

28. Wójcik, G.; Wieszczycka, K.; Aksamitowski, P.; Zembrzuska, J. Elimination of carcinogenic chromium(VI) by reduction at two-phase system. Sep. Purif. Technol. 2020, 238. [CrossRef]

29. Wieszczycka, K. Recovery of Zn(II) from multielemental acidic chloride solution with hydrophobic 3-pyridineketoxime. Sep. Purif. Technol. 2013, 114. [CrossRef]

30. Wieszczycka, K.; Wojciechowska, A.; Krupa, M.; Kordala-Markiewicz, R. Quaternary pyridinium ketoximes as zinc extractants from chloride solutions. J. Chem. Eng. Data 2013, 58. [CrossRef]

31. Wojciechowska, A.; Wieszczycka, K.; Wojciechowska, I. Efficient recovery of copper from aqueous solutions with pyridine extractants (oxime, ketone) and their quaternary pyridinium salts. Sep. Purif. Technol. 2017, 185. [CrossRef] 
32. Wieszczycka, K.; Filipowiak, K.; Wojciechowska, I.; Aksamitowski, P. Novel ionic liquid-modified polymers for highly effective adsorption of heavy metals ions. Sep. Purif. Technol. 2020, 236, 116313. [CrossRef]

33. Do, D.D. Adsorption Analysis: Equilibria and Kinetics. Analysis of Adsorption Kinetics in a Single Homogeneous Particle. Adsorpt. Anal. Equilibria Kinet. 1998, 2, 519-602. [CrossRef]

34. Wang, J.; Guo, X. Adsorption isotherm models: Classification, physical meaning, application and solving method. Chemosphere 2020, 258, 127279. [CrossRef]

35. El-Khaiary, M.I. Least-squares regression of adsorption equilibrium data: Comparing the options. J. Hazard. Mater. 2008, 158, 73-87. [CrossRef]

36. Nam, C.M.; Lee, J.S.; Kim, Y.G. Zirconium phosphonates layered structure catalysts with organic acid pendants 1. Preparation and physical properties. Korean J. Chem. Eng. 1993, 10, 93-99. [CrossRef]

37. Makovskaya, O.Y.; Kolmachikhina, O.B.; Lobanov, V.G.; Polygalov, S.E. Nickel sorption from solutions with high salt concentration. IOP Conf. Ser. Mater. Sci. Eng. 2020, 966, 012007. [CrossRef]

38. Sitko, R.; Turek, E.; Zawisza, B.; Malicka, E.; Talik, E.; Heimann, J.; Gagor, A.; Feist, B.; Wrzalik, R. Adsorption of divalent metal ions from aqueous solutions using graphene oxide. Dalt. Trans. 2013, 42, 5682-5689. [CrossRef] [PubMed]

39. Pullman, B.; Goldblum, N. (Eds.) Metal-Ligand Interactions in Organic Chemistry and Biochemistry. In Proceedings of the Jerusalem Symposia on Quantum Chemistry and Biochemistry, Jerusalem, Israel, 28-31 March 1977; Springer: Dordrecht, The Netherlands, 1977; Volumes 1-9, ISBN 978-94-010-1172-3.

40. Milios, C.J.; Stamatatos, T.C.; Perlepes, S.P. The coordination chemistry of pyridyl oximes. Polyhedron 2006, 25, 134-194. [CrossRef]

41. Demirbas, A.; Pehlivan, E.; Gode, F.; Altun, T.; Arslan, G. Adsorption of Cu(II), Zn(II), Ni(II), Pb(II), and Cd(II) from aqueous solution on Amberlite IR-120 synthetic resin. J. Colloid Interface Sci. 2005, 282, 20-25. [CrossRef]

42. Pehlivan, E.; Altun, T. Ion-exchange of $\mathrm{Pb}^{2+}, \mathrm{Cu}^{2+}, \mathrm{Zn}^{2+}, \mathrm{Cd}^{2+}$, and $\mathrm{Ni}^{2+}$ ions from aqueous solution by Lewatit CNP 80. J. Hazard. Mater. 2007, 140, 299-307. [CrossRef] [PubMed]

43. Zhao, G.; Huang, X.; Tang, Z.; Huang, Q.; Niu, F.; Wang, X. Polymer-based nanocomposites for heavy metal ions removal from aqueous solution: A review. Polym. Chem. 2018, 9, 3562-3582. [CrossRef]

44. Zhu, Y.; Hu, J.; Wang, J. Competitive adsorption of $\mathrm{Pb}(\mathrm{II}), \mathrm{Cu}(\mathrm{II})$ and $\mathrm{Zn}$ (II) onto xanthate-modified magnetic chitosan. J. Hazard. Mater. 2012, 221, 155-161. [CrossRef]

45. Vajdi, R.; Alvand, N.; Baghdadi, M.; Bidhendi, G.N. Increase of chitosan selectivity and affinity toward the cadmium ions using xanthate functionalization: Application for cadmium removal from saline solutions. J. Water Process. Eng. 2021, 40, 101898. [CrossRef] 